\title{
Automated Micropipette Aspiration of Single Cells
}

\author{
by
}

Ehsan Shojaei-Baghini

A thesis submitted in conformity with the requirements for the degree of Master of Applied Science

Graduate Department of Mechanical and Industrial Engineering University of Toronto

(c) Copyright 2012 by Ehsan Shojaei-Baghini 


\author{
Abstract \\ Automated Micropipette Aspiration of Single Cells \\ Ehsan Shojaei-Baghini \\ Master of Applied Science \\ Graduate Department of Mechanical and Industrial Engineering \\ University of Toronto \\ 2012
}

This research presents a system for mechanically characterizing single cells using automated micropipette aspiration. Using vision-based control and position control, the system controls a micromanipulator, a motorized translation stage, and a custom-built pressure system to position a micropipette ( $4 \mu \mathrm{m}$ opening) to approach a cell, form a seal, and aspirate the cell into the micropipette for quantifying the cell's elastic and viscoelastic parameters as well as viscosity. Image processing algorithms were developed to provide controllers with real-time visual feedback and to accurately measure cell deformation behavior on the fly. Experiments on both solid-like and liquid-like cells demonstrated that the system is capable of efficiently performing single-cell micropipette aspiration and has low operator skill requirements. Once the system was validated, it was used to study voided urine cells. In this study, the mechanical properties of bladder carcinoma cells were investigated. 


\section{Acknowledgements}

I would like to thank my adviser, Professor Yu Sun, for without his research guidance and encouragement this thesis would not have been possible. I wish to express my sincere appreciation and thanks to all the members of the Advanced Micro and Nanosystems Laboratory at the University of Toronto. I would like to thank Dr. William Geddie (Toronto General Hospital), Dr. Michael Jewett (Princess Margaret Hospital), Yi Zheng, and John Nguyen for their support and help. 


\section{Contents}

1 Introduction $\quad 1$

1.1 Cell Mechanical Characterization . . . . . . . . . . . . . 1

1.2 Correlation with Diseases . . . . . . . . . . . . . . . . 1

1.3 Characterization Techniques .................. 3

1.4 Micropipette Aspiration . . . . . . . . . . . . . . . 3

1.4.1 Manual Micropipette Aspiration . . . . . . . . . . . . . . . 4

1.4.2 Modeling of Mechanical Properties . . . . . . . . . . . . . . 6

1.5 Research Objectives . . . . . . . . . . . . . . . . 6

1.6 Dissertation Outline . . . . . . . . . . . . . . 7

2 System Setup $\quad 8$

2.1 Introduction . . . . . . . . . . . . . . . . . 8

2.2 Digital Pressure Pump . . . . . . . . . . . . . . . . . 11

2.2.1 Introduction . . . . . . . . . . . . . . . 11

2.2.2 Mechanical Design . . . . . . . . . . . . . . . . . . . 11

2.2 .3 Electrical Design . . . . . . . . . . . . . . . 14

2.2.4 Controller Design . . . . . . . . . . . . . . . . 14

2.2.5 Future Work. . . . . . . . . . . . . . . 14

2.3 Micromanipulator . . . . . . . . . . . . . . . . . . 17

2.3.1 Introduction . . . . . . . . . . . . . . . 17 
2.3 .2 Control Strategy . . . . . . . . . . . . . . . . . . 18

2.4 XY Translation Stage . . . . . . . . . . . . . . . . . . . . . . . 18

2.4 .1 Introduction $\ldots \ldots \ldots \ldots \ldots \ldots \ldots \ldots$

2.4 .2 Control Strategy . . . . . . . . . . . . . . . . 18

2.5 Micropipette Fabrication . . . . . . . . . . . . . . . . 20

3 Software Design $\quad 21$

3.1 Introduction . . . . . . . . . . . . . . . . . . 21

3.2 Image Processing . . . . . . . . . . . . . . . . . . . 21

3.2 .1 Micropipette Tracking . . . . . . . . . . . . . . . 22

$3.2 .2 \quad$ Cell Tracking . . . . . . . . . . . . . . . . . . . 22

3.2 .3 Aspiration Length Tracking . . . . . . . . . . . . . . . 24

3.3 Data Handling . . . . . . . . . . . . . . . . . . . . . . . 24

3.4 Software Operation . . . . . . . . . . . . . . . 26

4 Validation Experiments $\quad 30$

4.1 Sample Preparations . . . . . . . . . . . . . . . . . . . . 30

4.2 Experimental Protocols . . . . . . . . . . . . . . . . . . . . 31

4.3 Elastic Characterization . . . . . . . . . . . . . . . . 35

4.4 Viscoelastic Characterization . . . . . . . . . . . . . . . 36

4.5 Viscosity Characterization . . . . . . . . . . . . . . 37

5 Voided Urine Study $\quad 42$

5.1 Introduction . . . . . . . . . . . . . . . . 42

5.2 Materials and Methods . . . . . . . . . . . . . . . . . . . 44

5.2.1 Urine Preparation and Cell Selection . . . . . . . . . . . 44

5.3 Result and Discussion $\ldots \ldots \ldots \ldots \ldots \ldots$

5.4 Conclusion . . . . . . . . . . . . . . . . . . . . . . 48 
$\begin{array}{lll}6 & \text { Summary } & 52\end{array}$

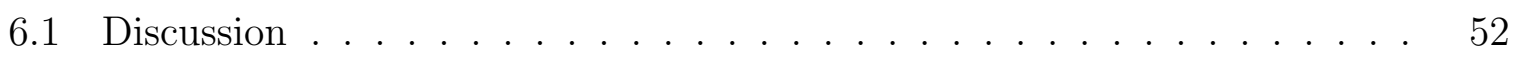

6.2 Conclusion . . . . . . . . . . . . . . . . . . . . 53

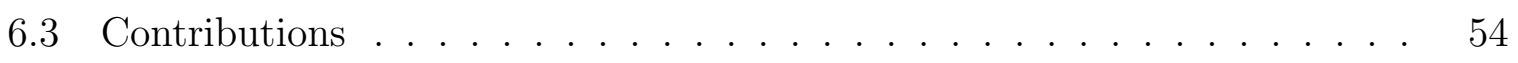

6.4 Future Works ......................... . . 54

$\begin{array}{ll}\text { Bibliography } & 55\end{array}$ 


\section{List of Tables}

2.1 Valve states in the digital pressure system . . . . . . . . . . . 13

4.1 Determined viscoelastic parameters of PAVICs . . . . . . . . . . . 37 


\section{List of Figures}

1.1 Cell characterization techniques. (a) Magnetic twisting cytometry; (b) Optical tweezers; (c) Atomic force microscopy; (d) Micropipette cell aspi-

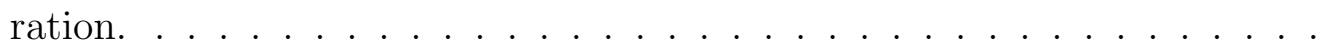

1.2 Deformation of a cell in response to an induced vacuum pressure into a

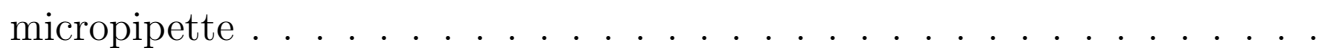

2.1 System for automated single-cell micropipette aspiration. (a) Micromanipulator with encoder feedback. (b) Custom-built computer-controlled pressure system. (c) Differential pressure transducer measuring the pressure difference between the delta and reference tanks. (d) Inverted microscope with motorized focus. . . . . . . . . . . . . . . .

2.2 System connectivity to the host PC. Two NI-6259 PCI Express cards were used to interface with the hardware. Each card can only handle two rotary encoders, so two are used to read all 4 axes of the micromanipulator. The inverted microscope and XY stage are controlled via COM port (RS-232). The CMOS camera is interfaced to the PC via FireWire. The custom-built pressure system is controlled using digital inputs/outputs (DIOs) of the second DAQ card. The output from the pressure transducer $(0-5$ VDC) is sampled using a 16-bit analog-to-digital converter (ADC) on the second

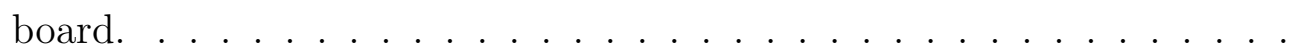


2.3 Digital pressure pump. (a) Solenoid valves are used in routing fluid. (b) High pressure air pump is used to remove trapped air from a newly mounted micropipette. (c) Delta Tank moves vertically to generate pressure. (d) Reference Tank moves vertically to balance the pressure in Delta Tank. (e) Differential pressure transducer outputs the pressure difference between Delta and Reference Tanks in Volts . . . . . . . . . . . .

2.4 Digital pressure pump. (a) Stepper motor 1 used to adjust the height of Delta tank. (b) Stepper motor 2 used to adjust the height of the Reference tank. (c) Differential pressure transducer measures the pressure difference between the two tanks. (d) Flexible couplers isolate vibration of stepper motors from the drive system. (e) Flexible rubber isolates the transducer from the vibration caused by the moving parts in the system. (f) Soft foam isolates the pressure system from the rest of the setup. (g) Driver board, solenoid valves, and other electronics assembly. . . . . . . . . . 15

2.5 Driver board for the digital pressure pump. (a) and (b) stepper motor drivers with $\frac{1}{16}$ microstepping capability. (c) Limit switches bounds the motion of the linear actuators to prevent damage to the system. (d) Transistor based drivers for actuating solenoid valves. 2N2222 (a common NPN bipolar junction transistor) used as a switch. (e) Communication bus connects the driver board to a digital IO lines of a NI PCIe-6259 board. . . .

2.6 System control architecture. (a) PID position controller for controlling the pressure system. (b) Image-based look-and-move visual servoing controller for controlling the micromanipulator. (c) PID position controller for controlling the motorized XY translation stage. $\ldots \ldots \ldots \ldots$

2.7 Pressure pump response to a step input of $100 \mathrm{~Pa}$ (vacuum pressure). Case1 is overdamped, Case2 is critically damped, and Case3 is underdamped. 17 
2.8 Micropipette controller. (a) Three cases of PID gains and implemented gain scheduling. (b) The visual tracking results of the cases. Despite the fast response in Case2, the induced vibration compromises the visual tracking performance. Thus, a slower set of gains (Case1) is chosen to provide a smooth, vibration-free motion at the micropipette tip. . . . . . 19

2.9 XY stage response to a step input of 200 pixel in $\mathrm{X}$-axis. Case1 is overdamped, Case2 is critically damped, and Case3 is slightly underdamped.

3.1 Micropipette tracking. (a) Search with the normalized cross-correlation algorithm within the search area. (b) User selects a template containing the micropipette tip. (c) Matched template location and angle $(x, y, \alpha)$.

3.2 Cell tracking. (a) ROI formed around user's click (green cross). (b) Binarized image with the Otsu adaptive thresholding method. (c) Morphological close operation creates a smooth object. (d) Morphological convex operation fills the holes and create an envelope of the cell. (e) Noise removal based on object area. (f) Least square fitting to obtain a circle $\left(x, y, R_{c}\right) \ldots \ldots \ldots \ldots \ldots$

3.3 Cell aspiration length tracking. (a) ROI containing the inside of the micropipette. (b) Sobel filter is used to enhance the edges and remove vertical edges. (c) The tracked aspiration length is highlighted in green, and the area between the dashed red lines is termed 'safe zone'. . . . . . . . . . 
3.4 Automated micropipette aspiratation GUI. Commands (tasks) that are executed in order. Test type determines the experiment (elastic, viscoelastic, or viscose). System settings are the settings for each individual command (task). Device settings are the setup parameters for the hardware connected to the PC. The top-right corner presents a live video of the cell under experiment. The bottom-right graphs present real-time measurements of aspiration length, applied pressure, and cell radius. Between the live video and graphs, the system logs all the activities including errors. .

3.5 System settings. (a) Allows the user to select the setup of the experiment before starting the automated process. This section grants the user access to all the connected hardware via $3 D$ mouse. (b) Settings for finding the template in the focal axis of the microscope. This section contains the settings for the depth of sweep, and template definition. (c) Settings for centering the cell in the image. This section contains PID gain parameters for XY stage, expected cell radius and measured cell radius. (d) Settings for homing micropipette. This section contains the micromanipulator PID gain parameters, and relative position of the "home" as a percentage of the image height. (e) These settings define the seal making parameters. In particular, the PID gain parameters for the micromanipulator are set to create a slow movement of the tip to prevent disturbance. (f) These are the experiment parameters such as the interval between pressure decreases

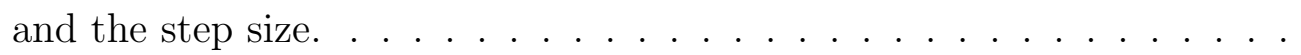


3.6 Device settings. (a) These settings adjust the PID loop of the custombuilt pressure pump such as PID gain parameters, voltage-to-frequency converter, low-pass filter, and error band. (b) Settings for the camera such as the name, brightness, contrast, and shutter values. (c) The settings for microscope such as the light intensity level, magnification, and communication port. (d) These settings are for the inner-loop of the micromanipulator which works based on gain scheduling. . . . . . . . . .

4.1 Automated micropipette aspiration process. (a) Locating the micropipette tip using the pre-defined template. (b) Moving the micropipette to the top-right corner and centering the selcted cell to the center of the image. Micropipette is located such that its axis passes through the center of the image (cell). (c)-(d) The micropipette moves to the proximity of the cell slowly without touching the cell. (e) The seal pressure $P_{\text {seal }}$ causes the cell to move towards the tip and creating a seal between the micropipette tip and the cell. (f) Induced pressure causes the cell to deform into the micropipette and the imaging system captures the aspiration length during

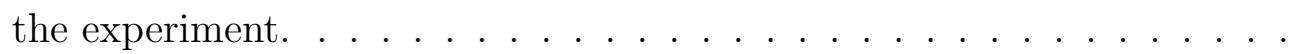

4.2 Automated micropipette aspiration flow chart. (a) Task 1 finds and parks the micropipette in home position. (b) Task 2 selects a target cell. (c) Task 3 creates a seal between the mouth of the micropipette and the cell. (d) Task 4 generates a specific pressure profile based on the experiment type. (e) Task 5 performs data analysis and calculates biomechanical properties of the tested cell. . . . . . . . . . . . . . . . . . . 
4.3 Pressure profile used to test PAVICs. A -70 Pa was used to make a seal between the cell and the micropipette tip. After an interval of 100 seconds, the pressure was decreased by $100 \mathrm{~Pa}$. The aspiration length is averaged for 10 seconds at the very end of each interval representing the deformation in that pressure level. . . . . . . . . . . . . . . .

4.4 Elastic and viscoelastic responses of PAVICs. $L$ is the aspiration length and $R_{p}$ is the radius of the micropipette. (a) Elastic response of a PAVIC, where (i)-(iv) are equilibrium points at the end of 100-second intervals. (b) Viscoelastic response of a PAVIC. A step pressure of $-400 \mathrm{~Pa}$ was applied for 150 seconds. . . . . . . . . . . . . . . . .

4.5 Viscous properties of HL-60 cells. (a) Viscous response of an HL-60 cell to a step pressure of $-270 \mathrm{~Pa}$. (i)-(iv) show the cell at various time instances. $L$ is the aspiration length and $R_{p}$ is the radius of the micropipette. (b) Cytoplasmic viscosity as a function of mean shear rate $\gamma_{m}$. Step pressure varied from $-700 \mathrm{~Pa}$ to $-220 \mathrm{~Pa}(n=30) \ldots \ldots \ldots$

5.1 Representative morphologies of different urothelial cells present in human voided urine. (a) Basal cell, (b) umbrella cell, (c) intermediate cell and (d) cancerous urothelial cell

5.2 Young's Modulus results from micropipette aspiration testing of voided urine. (a) Young's modulus of normal intermediate cells (460 $\pm 50 \mathrm{~Pa}, n=$ 13) and cancerous urothelial cells $(200 \pm 40 \mathrm{~Pa}, n=17)$. (b) Young's modulus of normal intermediate cells (460 $\pm 50 \mathrm{~Pa}, n=13)$, cancerous urothelial cells with high $\mathrm{NC}$ ratio $(300 \pm 60 \mathrm{~Pa}, n=8)$ and cancerous urothelial cells with low $\mathrm{NC}$ ratio $(84 \pm 17 \mathrm{~Pa}, n=9) . \quad . . . .$. 
5.3 Comparison among three categories of cells. Experimental curve of normalized aspiration length vs. aspiration pressure of typical normal intermediate cells (red), cancerous urothelial cells with high $\mathrm{NC}$ ratio (blue) and cancerous urothelial cells with low $\mathrm{NC}$ ratio (black). . . . . . . .

5.4 Scatter plot of NC ratio vs. Young's Modulus of normal intermediate cells and cancerous urothelial cells with both high $(<0.3)$ and low $(>0.3)$ NC ratio $(n=17)$. Data points of different shapes with the same color group present different donors. When the tumor cells have comparable NC ratio with normal intermediate cells, the Young's Modulus of cells can be used as an additional bio-marker, along with the $\mathrm{NC}$ ratio (morphological marker), the cells type can be better interpreted. . . . . . . . . . . . 51 


\section{Chapter 1}

\section{Introduction}

\subsection{Cell Mechanical Characterization}

Population-based cell experiments do not permit a thorough examination of the stochastic processes involved in regulating cellular function at the single cell level [1]. On the other hand, the study of individual living cell mechanics helps gain insight in to cell structures, functions, and heterogeneity [2].

The internal scaffolding of a cell consists of a complex network that determines the cell's shape and mechanical properties. Actin filaments are one of the cytoskeletal elements that contribute to the mechanical properties of the cell and participates in muscle contraction, cell motility and cell division. Intermediate filaments are deformable proteins that play a huge role in deformation of the cell [3-5].

\subsection{Correlation with Diseases}

Living cells are capable of sensing the mechanical stimuli around them and reflect them as biological responses [3]. Moreover, any change to the the cell's functions due to biochemical alterations can affect the mechanical properties of the cell. These biochemical changes within the human body could be due to disease development or foreign organisms [6]. 
It has been demonstrated that single-cell mechanical characterization can also be useful for investigating disease mechanisms and progression $[7,8]$, since the biomechanical properties of the pathological cells can differ from healthy ones. For instance in arthritis, an increase in stiffness and viscosity of the chondrocytes (in charge of cartilage maintenance) is observed. One of the factors that is known to alter the chondrocytes metabolism is the biophysical factors generated by mechanical loading of the joints. Thus, in some cases abnormal mechanical factors can change the cellular behavior of the cells causing joint degenerations [9].

In asthma, the airway muscle cells stiffening causes shortness of breath and coughing. The key end-effector of acute airway narrowing is the airway smooth-muscle (ASM) cells. The study of the cytoskeleton ability of the ASM cells to stiffen sheds light on new perspectives on the ASM and how it affects the airway narrowing in asthma patients [10].

Red blood cells (RBCs) are in charge of oxygen transport to various parts of the body. Their deformablity allow them to squeeze their way through narrow capillaries. In malaria, both rigidity and stickiness of RBCs are increased which damages the blood flow that can result in anemia, coma and death. The study of RBCs at the cellular level has shown that the infection of RBCs can impair their rheological properties [11-20].

In sickle-cell anemia, RBCs are known to stiffen and assume a rigid sickle like shape. The deformability of RBCs plays an important role in blood flow circulation in capillaries. Studies on the deformability, viscosity, and geometril features of RBCs shed light on the significance of mechanical properties role in sickle-cell anemia [21-24].

Mechanical characterization of cells from the pleural fluids of patients revealed that the Young's modulus of cancer cells is considerably less than in benign cells [8]. In late stages of bladder carcinoma, the cell nucleus is observed to grow larger in tumor cells and occupy more of the cell. In this study, the increased stiffness of tumor cells in voided urine is correlated to a higher nucleus to cytoplasmic ratio. This observation is discussed in detail in Chapter 5 of this thesis. 


\subsection{Characterization Techniques}

The need of investigating biomechanics at the cellular level calls for single cell manipulation techniques for studying the complex and dynamic behavior of individual cells. Over the years, many methods have been developed to study mechanical properties of single cells.

In magnetic twisting cytometry (MTC), magnetic beads are attached to the cell surface. Twisting moments induced by the application of a magnetic field causes the cell to deform (Fig. 1.1(a)). Both elastic and viscoelastic properties of cells can be measured using this technique $[3,10,11,25]$.

In optical tweezers (OT), laser beams trap high-refractive-index dielectric beads attached to cells (Fig. 1.1(b)) and hence, exert forces on the cells $[2,6,7,11,26]$. The applied force from optical tweezers is typically limited to a few hundred pN. More experimental single-cell mechanical characterization techniques were reviewed in [2].

In atomic force microscopy (AFM), mechanical deformation is induced using the tip of a cantilever. The deflection of the cantilever is used to calculate the applied force (Fig. 1.1(c)). Using this technique, a map of cell stiffness across the cell surface can be generated $[2,6,11,27]$.

\subsection{Micropipette Aspiration}

Another technique used to characterize the mechanical properties of living cells is micropipette aspiration. This technique (which is the focus of this research) uses a fine hollow needle to aspirate a portion of a cell with a vacuum pressure transmission system (Fig. 1.2(d)(i-ii)). The vacuum pressure is usually applied by means of a height difference between the micropipette tip and the water reservoir. Water-filled tubings connect the micropipette tip to the reservoirs.

Geometric changes in cell shape are measured (Fig. 1.2(d)(iii)) to determine the elastic 


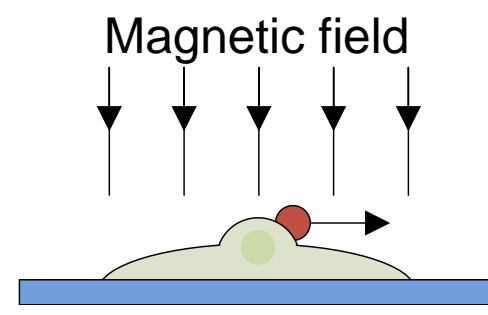

(a)

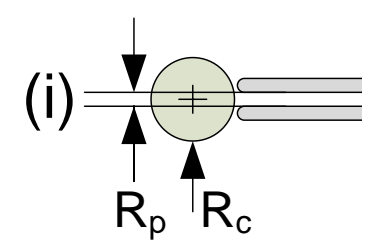

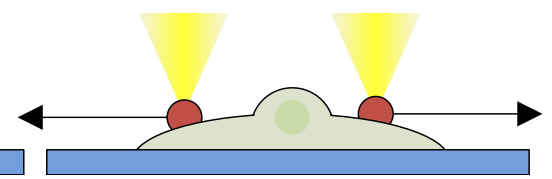

(b)

(ii)

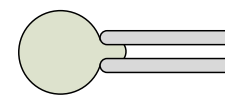

(d)

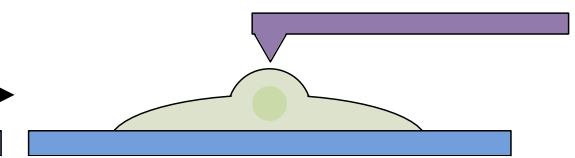

(c)

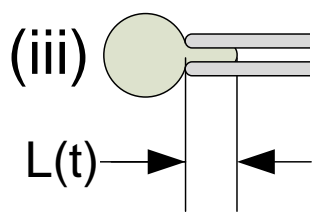

Figure 1.1: Cell characterization techniques. (a) Magnetic twisting cytometry; (b) Optical tweezers; (c) Atomic force microscopy; (d) Micropipette cell aspiration.

and viscoelastic properties, and flow resistance of the cell $[2,6,28-34]$. The cell deformation is usually measured by means of a video microscopy system that is mounted to the microscope.

A simple illustration of micropipette aspiration is presented in (Fig. 1.1(d)). In this example, the micropipette tip and cell are aligned such that the axis of the pipette passes through the center of the cell (Fig. 1.1(d)(i)). A weak vacuum pressure (negative pressure with respect to the micropipette tip) is applied to the tip to create a seal between the cell and the micropipette (Fig. 1.1(d)(ii)). The application of pressure causes deformation of the cell into the micropipette (Fig. 1.1(d)(iii)). These changes $(L(t))$ are recorded and used to extract the mechanical properties of the cell (Fig. 1.2).

\subsubsection{Manual Micropipette Aspiration}

Conventionally, micropipette aspiration requires well-trained operators to look into the eyepieces of a microscope, skillfully operate multiple devices to micromanipulate single cells, control vacuum pressure at proper timings to form a seal between the cell and 


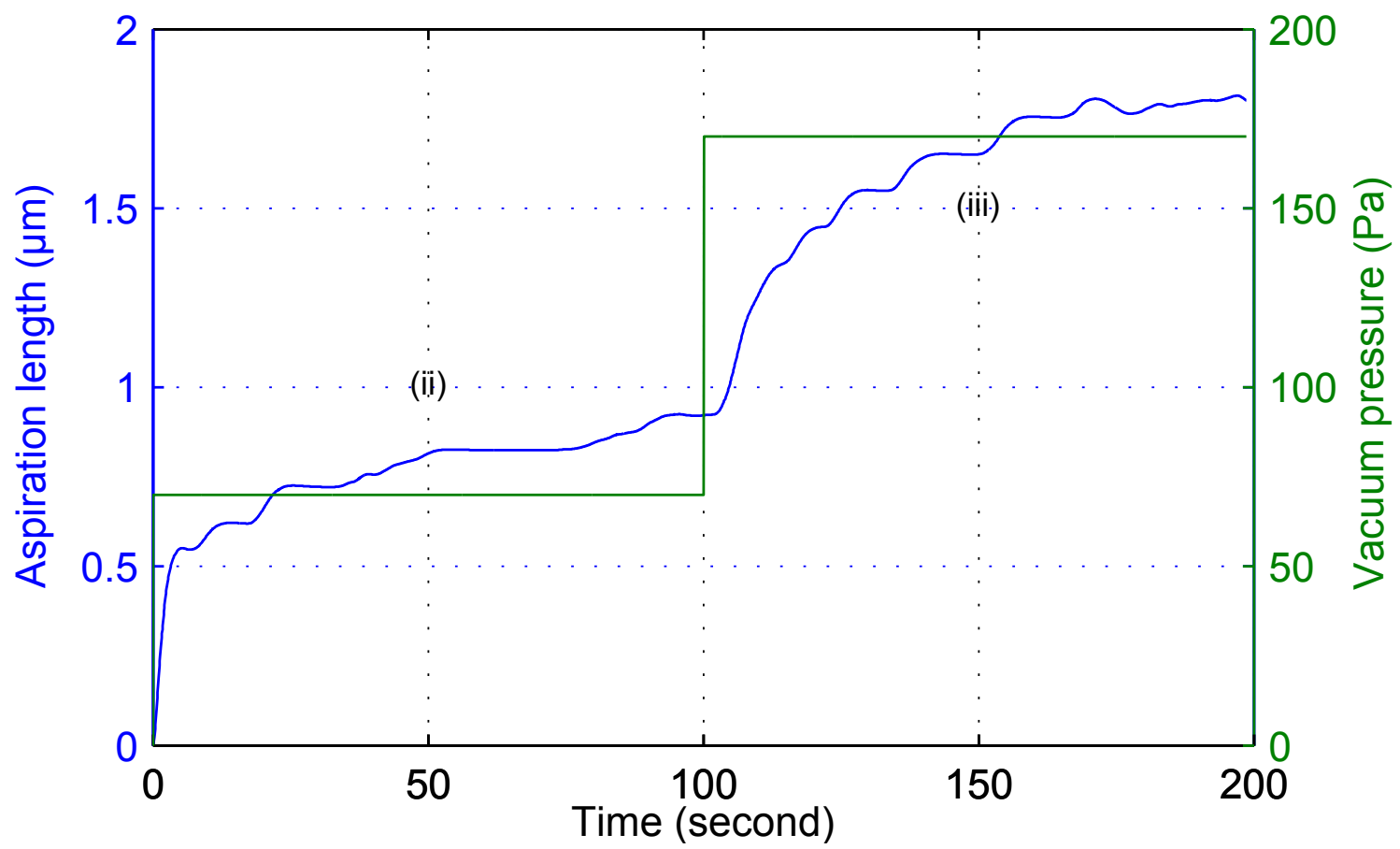

Figure 1.2: Deformation of a cell in response to an induced vacuum pressure into a micropipette

micropipette opening, synchronize pressure and video recording, and accurately measure recorded images to extract cell deformation parameters. After cell experiments, the operator determines cell deformations by performing manual measurements on a high number of recorded images.

In cases of using this technique on suspended cells such as RBCs, the cells are in their natural state; however, in cases of testing adherent cells, due to detachment of cells from the substrate, the cells are softened and not in their natural state. The extracellular matrix softens the cell because of the relieved stress at focal adhesion points $[35,36]$.

Micropipette aspiration is a powerful technique and has low infrastructure requirements. However, the high skill requirements and the efforts required for tedious, timeconsuming post processing of data make the technique difficult and less appealing to use. In contrast, AFM over the past decade has been largely automated. The automated operation of AFM ('point-and-click') is part of the reason why AFM has become a more 
widely used research tool in cell mechanics.

\subsubsection{Modeling of Mechanical Properties}

Mechanical properties of cells are extracted from models that are based on the continuum approach. In this approach, the cell is assumed to have homogeneous material properties. Various models have been developed to characterize the mechanical properties of living cells when subjected to mechanical stimuli [37].

Suspended single cells can be either categorized as solid- or liquid-like cells. The difference between the two is in their response to an external mechanical load (vacuum pressure applied via a micropipette tip). Once the hemisphere projection is formed, the deformation of solid-like cells reaches a steady-state equilibrium in response to a decrease in pressure [29,31]. This behavior has been observed and reported in chondrocytes [38] and endothelial cells $[32,39]$, whereas the liquid-like cells will flow completely into the micropipette in response to a decrease pressure [40]. The liquid-like behavior has been reported in neutrophils [33,40] and erythrocytes [41].

\section{$1.5 \quad$ Research Objectives}

This study aims to prove the feasibility of achieving 'point-and-click' operation in micropipette aspiration through the use of automation techniques. In [42] and our previous work [43], image processing algorithms were developed to measure cell deformation behavior. This paper reports on an automated system that performs the complete micropipette aspiration procedure via computer mouse clicking. The system controls motion control devices based on visual servoing and position control and processes images in real time for tracking features and measuring cell shape changes. 


\subsection{Dissertation Outline}

This thesis is organized into the following chapters: chapter 2 describes the system for the automated micropipette aspiration; chapter 3 presents the custom software that runs the automated process and focuses on the image processing techniques used in this project; chapter 4 reports on the process that was used to validate the experimental results with reported values in the literature; chapter 5 presents the study of mechanical properties of cells found in voided urine; chapter 6 provides a summary of this research and the possible future works in this area. 


\section{Chapter 2}

\section{System Setup}

\section{$2.1 \quad$ Introduction}

In order to automate the micropipette aspiration process the following components were used (shown in Fig. 2.1): (1) an inverted microscope (Olympus IX81) with a CMOS camera (Basler A601f), to enable visual feedback for measuring and positioning purposes; (2) a motorized micromanipulator (Siskiyou, 7600 series) with encoder feedback for positioning of the micropipette; (3) an XY translation stage (Prior Scientific ProScan II) for positioning cell samples and (4) a custom-developed pressure system for generating computer-controlled vacuum levels using a differential pressure transducer (Omega PX409 - 10WDWU5V) to obtain pressure feedback.

The aforementioned components were controlled via a PC running custom-built LabVIEW (National Instruments) code. Fig. 2.2 illustrates the connectivity of these components to the PC. 


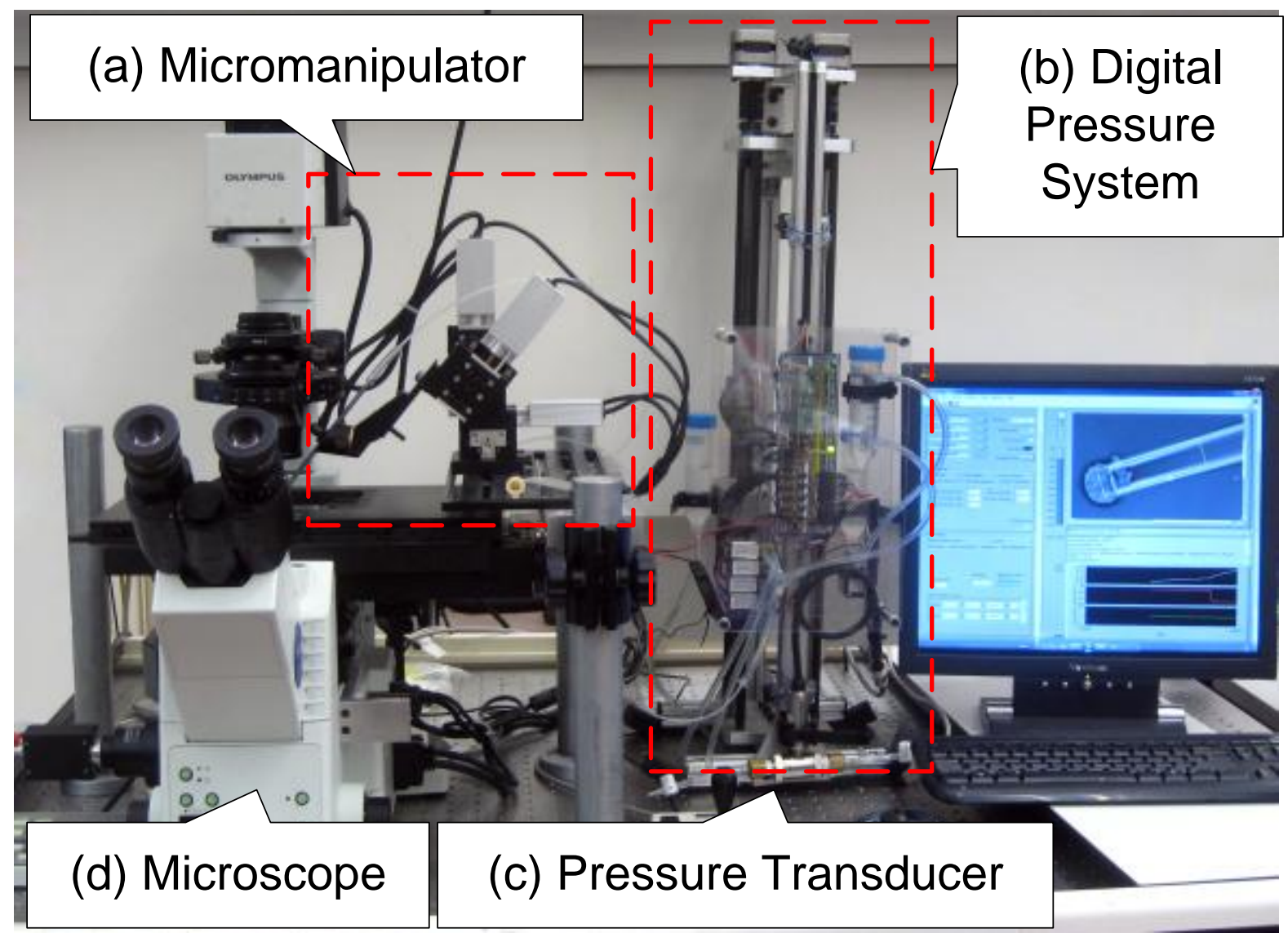

Figure 2.1: System for automated single-cell micropipette aspiration. (a) Micromanipulator with encoder feedback. (b) Custom-built computer-controlled pressure system. (c) Differential pressure transducer measuring the pressure difference between the delta and reference tanks. (d) Inverted microscope with motorized focus. 


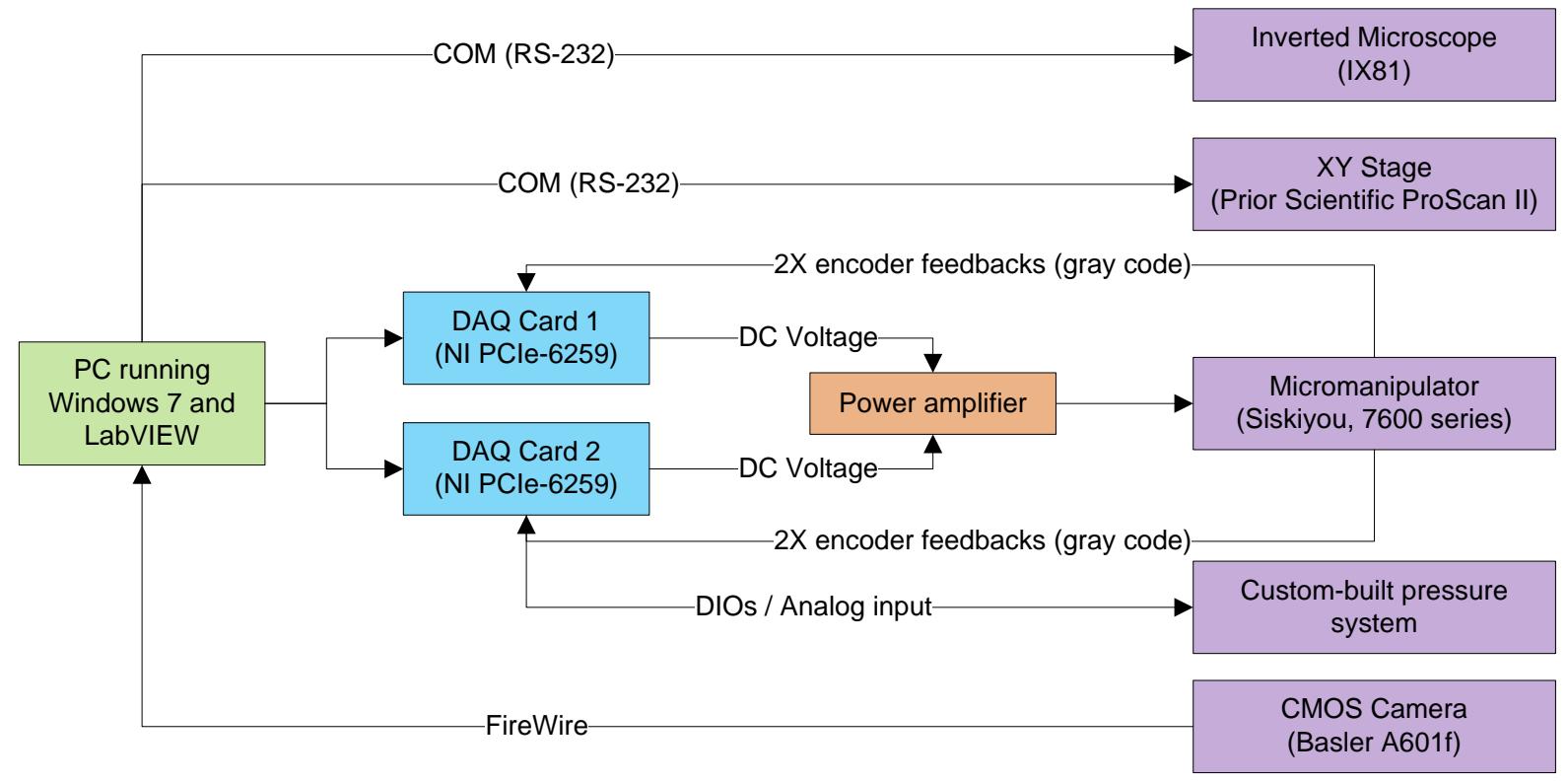

Figure 2.2: System connectivity to the host PC. Two NI-6259 PCI Express cards were used to interface with the hardware. Each card can only handle two rotary encoders, so two are used to read all 4 axes of the micromanipulator. The inverted microscope and XY stage are controlled via COM port (RS-232). The CMOS camera is interfaced to the PC via FireWire. The custom-built pressure system is controlled using digital inputs/outputs (DIOs) of the second DAQ card. The output from the pressure transducer (0 - 5 VDC) is sampled using a 16-bit analog-to-digital converter (ADC) on the second board. 


\section{$2.2 \quad$ Digital Pressure Pump}

\subsubsection{Introduction}

To create the vacuum pressure, the simplest method was to connect the micropipette to a pressure transducer and a variable height water tank. The measured pressure would be in absolute Pa. The vacuum pressure (differential negative pressures) required for this project was about $1000 \mathrm{~Pa}$, so the measured pressure from the transducer would be around $101,000 \pm 1000 \mathrm{~Pa}$. In practice, the measurement accuracy decreased dramatically due to small changes with respect to the full-scale measurement range. In other words, we are interested only in the $1000 \mathrm{~Pa}$ differential pressure but were using a large range sensor with larger errors in accuracy. To overcome this issue, a differential pressure transducer with a full range of $\pm 2500 \mathrm{~Pa}$ was used. Using a differential pressure transducer improved the accuracy of the measurements significantly.

In the implemented design [42], the suction pressure $(\Delta P=\rho g \Delta h)$ is generated by creating a height difference between the reference and delta tanks (Fig. 2.3 and Fig. 2.4). The reference tank and microscope slide on which the cells were tested was set at the same height. This ensured that the measured pressure at zero height difference and atmospheric pressure matched. During experiments, the delta tank was moved downwards to create vacuum pressures (differential negative pressures).

\subsubsection{Mechanical Design}

A custom-built aluminum frame served as a structure for two stepper motor driven linear actuators (Fig. 2.4(a)-(b)). These actuators were used to adjust the heights of the water tanks. The differential pressure transducer (Fig. 2.4(c)) was also mounted on the bottom of the structure.

Since the pressure system was mounted on the same vibration isolation table as the microscope, any vibration would compromise the imaging and positioning of the mi- 


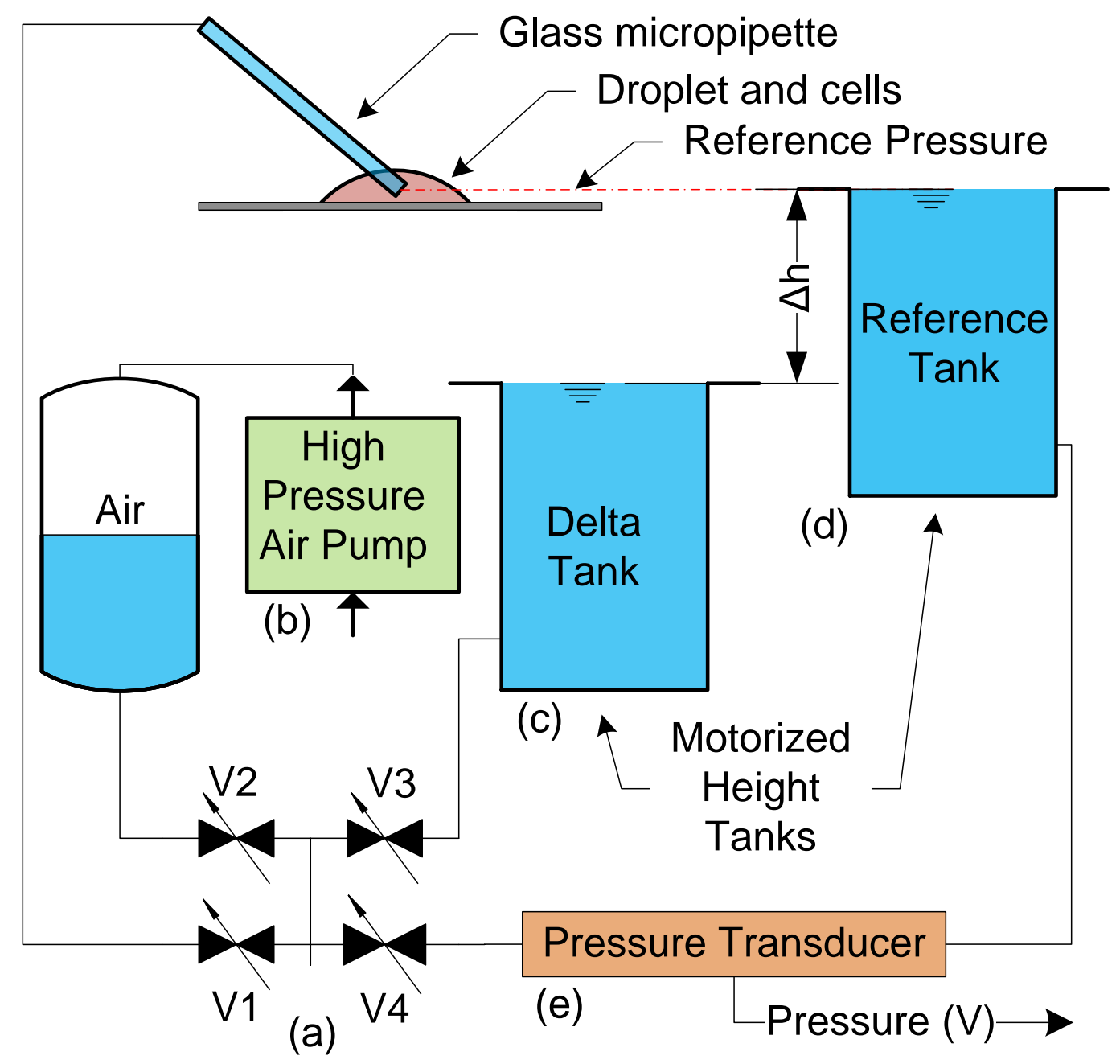

Figure 2.3: Digital pressure pump. (a) Solenoid valves are used in routing fluid. (b) High pressure air pump is used to remove trapped air from a newly mounted micropipette. (c) Delta Tank moves vertically to generate pressure. (d) Reference Tank moves vertically to balance the pressure in Delta Tank. (e) Differential pressure transducer outputs the pressure difference between Delta and Reference Tanks in Volts 
Table 2.1: Valve states in the digital pressure system

\begin{tabular}{llcccc}
\hline State & Description & V1 & V2 & V3 & V4 \\
\hline 1 & Sense Pressure & C & O & O & O \\
2 & Sense and apply pressure & O & C & O & O \\
3 & Route high pressure to micropipette only & O & O & C & C \\
4 & Route high pressure to Delta tank only & C & O & O & C \\
\hline
\end{tabular}

$\mathrm{O}$ and $\mathrm{C}$ represent Open and Close, respectively.

cropipette. Thus, vibration isolation was taken into consideration during design and fabrication of the pressure system. The stepper motors were connected to the drive system via flexible couplers (Fig. 2.4(d)). The pressure transducer was mounted using flexible rubber (Fig. 2.4(e)). Soft foam (Fig. 2.4(f)) was sandwiched between the system and the table to damp any vibration created during stepper motor driving.

Solenoid valves (Fig. 2.3(a)) were used to route the fluid for various functions.

During the trial and error process to adjust the PID gain parameters for the pressure system, V1 was kept closed to avoid disturbing the water due to leakage (state 1 in Table 2.1). During the experiment where the pressure is applied to the micropipette tip, all valves were kept open except V2 which connected the high pressure tank to the water circuit (state 2 in Table 2.1). In the beginning of an experiment when the operator mounts a new micropipette using the back filling method [42], the trapped air could be forced out by routing the high-pressure pump (Fig. 2.3(b)) to the micropipette tip without damaging the transducer (Fig. 2.3(e)) or affecting the water levels in reservoirs (state 3 in Table 2.1). In order to remove the built up bubbles in the water circuit, the high pressure tank is routed to the circuit to push all the gas to open water (state 4 in Table 2.1). 


\subsubsection{Electrical Design}

A custom-built driver board (Fig. 2.5) controlled the stepper motors and the solenoid valves using a digital communication bus from the PC. The stepper motors were driven by two A4988 stepper motor driver modules (Pololu) (Fig. 2.5(a)-(b)). Each driver controlled the motion of the stepper motor using 5 digital signals: (1) direction, (2) step, (3)-(5) microstepping. The four limit switches (two for each actuator) were connected to digital inputs using pull-down resistors (Fig. 2.5(c)). Four 2N222 NPN bipolar transistors were used as digital switches to drive the solenoid valves from digital outputs (Fig. 2.5(d)). A typical computer power supply was used to power all the valves and the pressure transducer via the driver board. The pressure transducer produced a conditioned $0-$ 5 VDC output proportional to the pressure difference at the inlets. This signal was sampled by a 16-bit analog to digital converter on the NI PCIe-6259 data acquisition board (Fig. 2.2).

\subsubsection{Controller Design}

The positions of the two water tanks were controlled by a standard proportional integral derivative (PID) controller ( $\pm 2 \mathrm{~Pa}$ differential error) with pressure feedback from the differential pressure transducer as illustrated in Fig. 2.6(a). The measured voltage from the pressure transducer was sampled then converted to pressure units in a LabVIEW implemented PID control loop (Fig. 2.7). The output of the controller was then converted to steps using a Delta-sigma modulator [44].

\subsubsection{Future Work}

The response time of the pressure pump to a step input could be increased by speeding up the linear actuator. This could be accomplished by using multiple-start threads instead of single start ones that were used in the current setup. In addition, timing belts and 


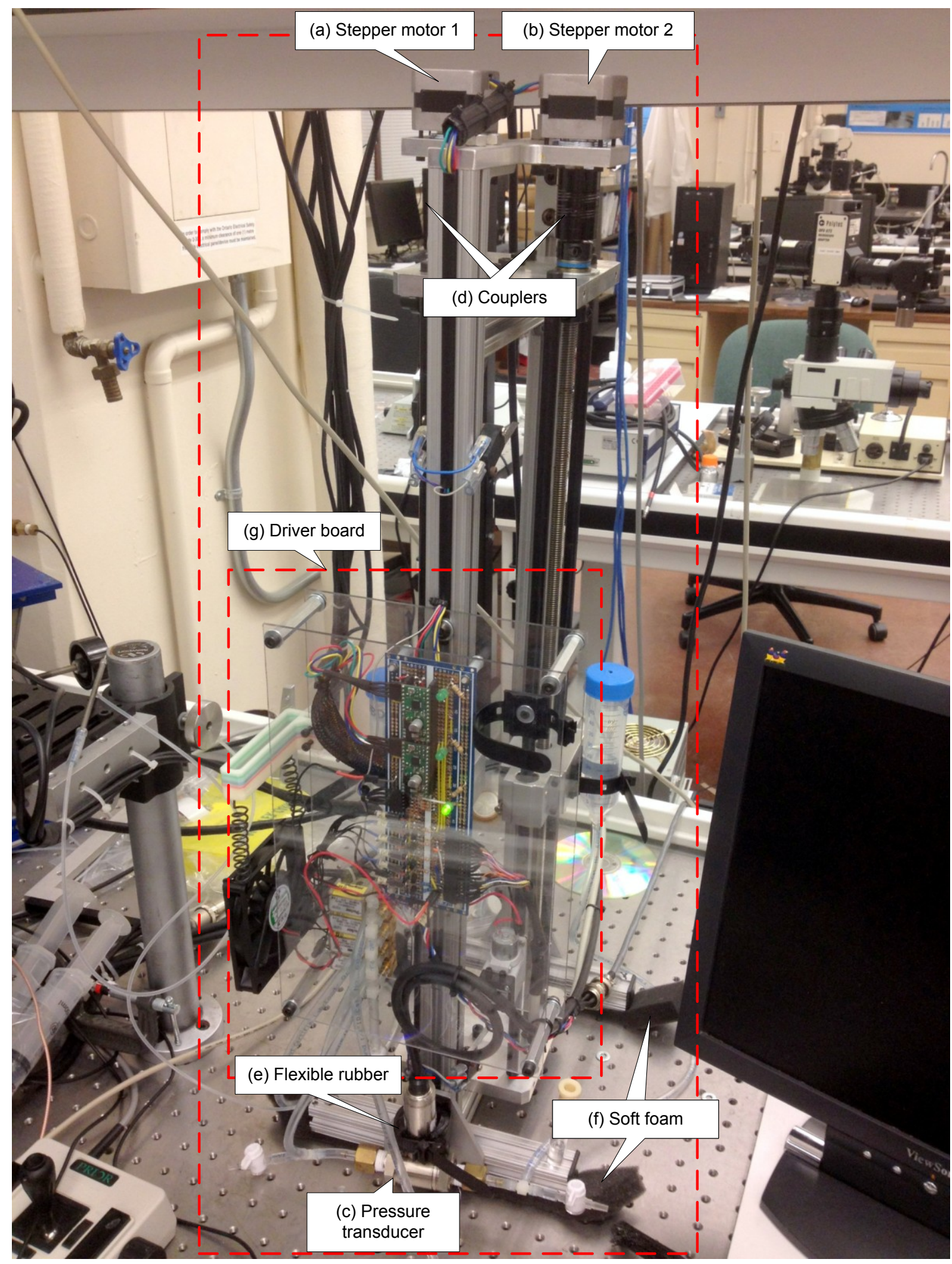

Figure 2.4: Digital pressure pump. (a) Stepper motor 1 used to adjust the height of Delta tank. (b) Stepper motor 2 used to adjust the height of the Reference tank. (c) Differential pressure transducer measures the pressure difference between the two tanks. (d) Flexible couplers isolate vibration of stepper motors from the drive system. (e) Flexible rubber isolates the transducer from the vibration caused by the moving parts in the system. (f) Soft foam isolates the pressure system from the rest of the setup. (g) Driver board, solenoid valves, and other electronics assembly. 


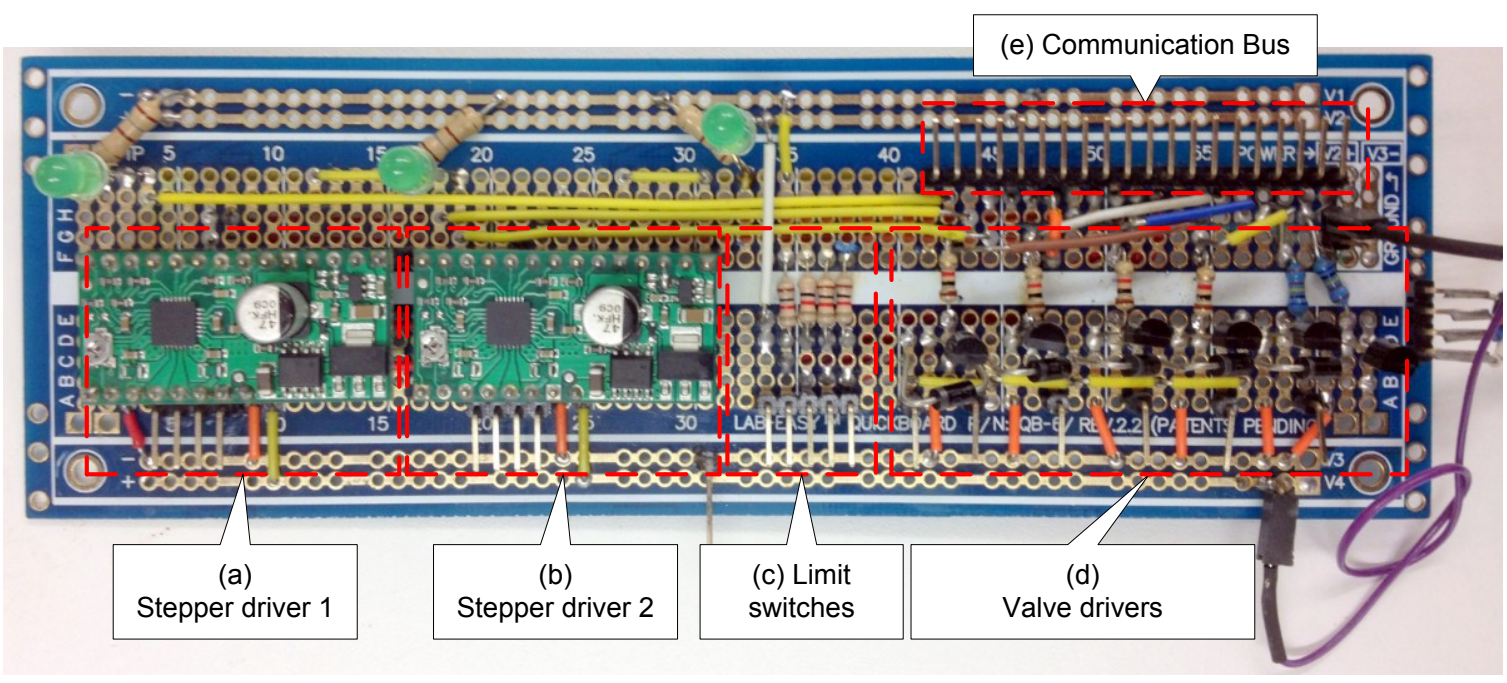

Figure 2.5: Driver board for the digital pressure pump. (a) and (b) stepper motor drivers with $\frac{1}{16}$ microstepping capability. (c) Limit switches bounds the motion of the linear actuators to prevent damage to the system. (d) Transistor based drivers for actuating solenoid valves. 2N2222 (a common NPN bipolar junction transistor) used as a switch. (e) Communication bus connects the driver board to a digital IO lines of a NI PCIe-6259 board.

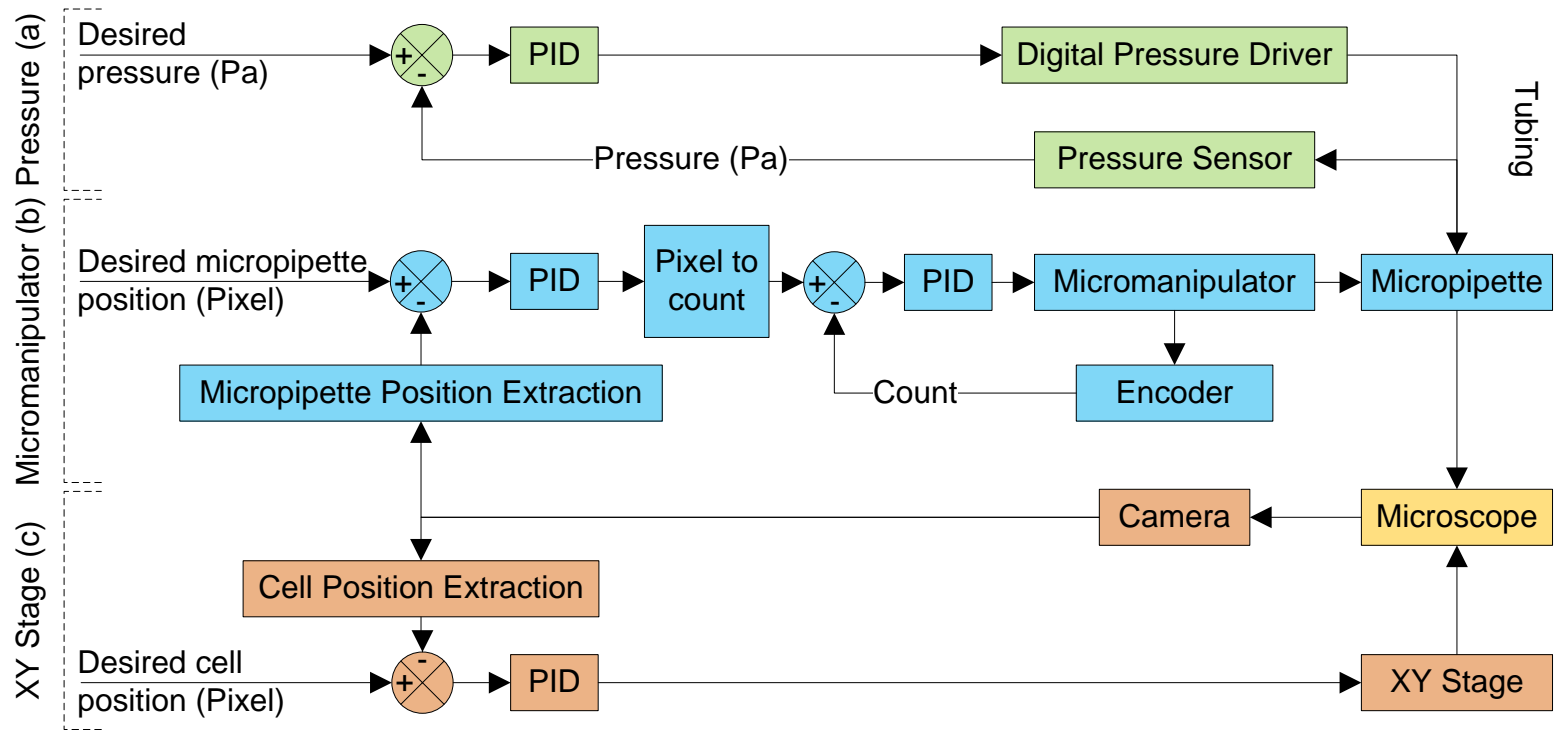

Figure 2.6: System control architecture. (a) PID position controller for controlling the pressure system. (b) Image-based look-and-move visual servoing controller for controlling the micromanipulator. (c) PID position controller for controlling the motorized XY translation stage. 


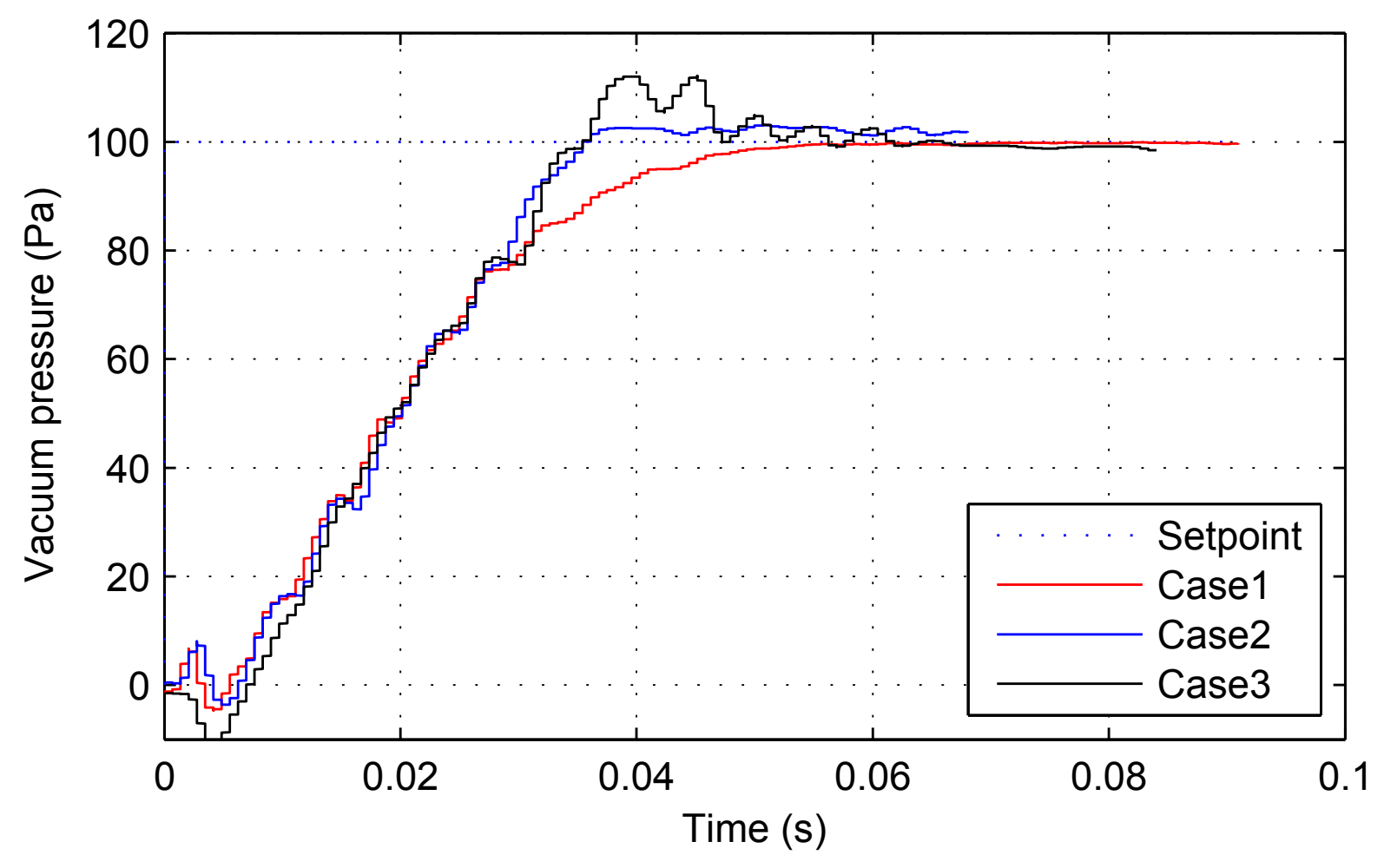

Figure 2.7: Pressure pump response to a step input of $100 \mathrm{~Pa}$ (vacuum pressure). Case1 is overdamped, Case 2 is critically damped, and Case 3 is underdamped.

pulleys could be used as linear actuators to dramatically improve the linear speed of the actuators.

\subsection{Micromanipulator}

\subsubsection{Introduction}

A motorized three degrees of freedom (DOF) micromanipulator (Siskiyou, 7600 series) used to accurately position the micropipette in the proximity of the living cells. Poorpositioning of the micropipette in any of the three axes could damage the cells or compromise the results of the tests. Each axis on the micromanipulator is driven by a DC motor powered by an amplifier and its position is measured by rotary encoders. Using two NI PCIe-6259 data acquisition boards, the motors were controlled by a DC voltage and the position was measured from the rotary encoders. 


\subsubsection{Control Strategy}

The micromanipulator was controlled via an image-based look-and-move visual servoing algorithm [45]. The internal closed-loop controller used encoders as input with a sampling rate of $1 \mathrm{kHz}$, whereas the visual servoing controller had a low sampling rate of $30 \mathrm{~Hz}$ (Fig. 2.6(b)).

Gain scheduling is one of the most popular nonlinear controller design approaches and is widely used $[46,47]$. Gain scheduling can be used to improve the performance of a PID controller. Basically, gain scheduling changes the PID gain parameters of a controller on-the-fly based on a defined variable.

In the implemented controller, the gain scheduler switches between two sets of gain parameters based on the magnitude of the error. In large errors (larger than $3 \mu m$ ), the algorithm uses a fast $\mathrm{P}$ controller (Fig. 2.8(a)); However, in small errors (smaller than $3 \mu \mathrm{m}$ ), the algorithm uses a relaxed and slow PI controller. This ensures a smooth motion and minimizes micropipette vibrations (Fig. 2.8(b)).

\subsection{XY Translation Stage}

\subsubsection{Introduction}

A motorized XY stage (Prior Scientific ProScan II) was used to position the cells in a standard Petri dish placed under the inverted microscope. This provided access to more cells by translating the stage. This functionality was also used in the automation process to position the cell in the center of the image during experiments.

\subsubsection{Control Strategy}

The motorized XY translation stage that was also controlled via image-based look-andmove visual servoing, as shown in Fig. 2.6(c). The PID controller sent velocity commands 


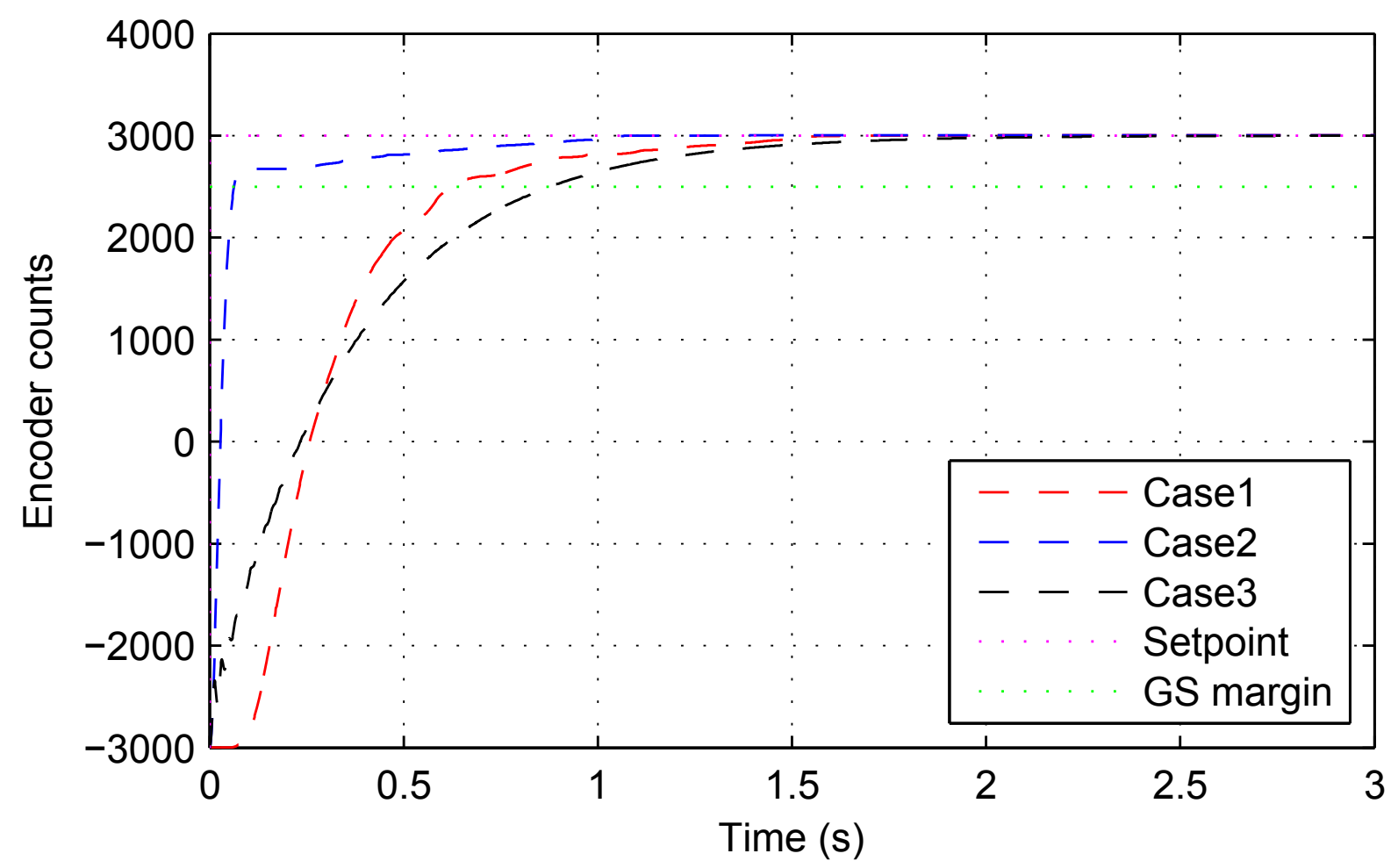

(a) Micromanipulator response to a step input of 3000 counts. The gain scheduling margin (GS) is 500 counts. Case1 is critically damped. Case2 is critically damped with a relaxed PI controller for small error magnitudes. Case3 is overdamed.

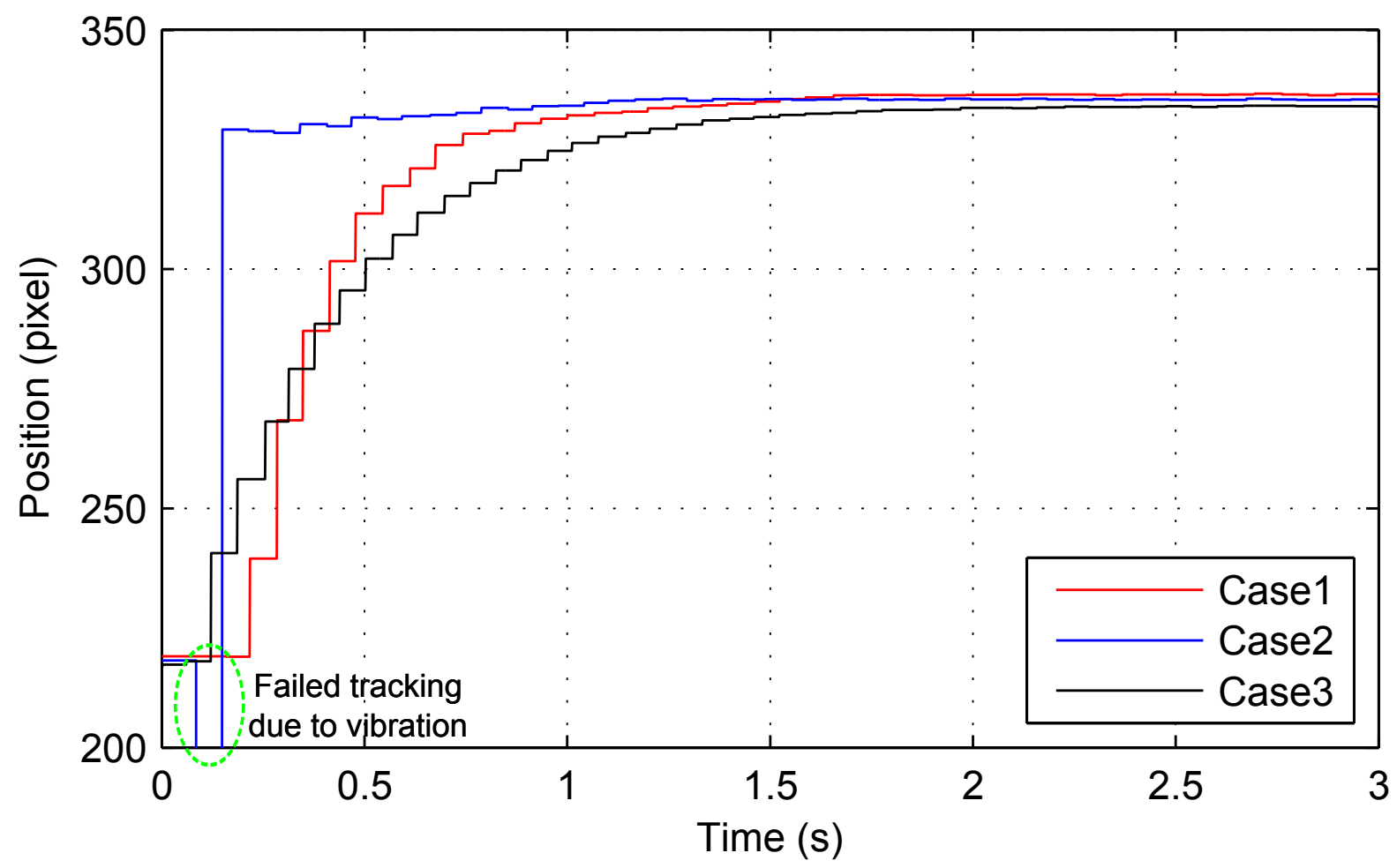

(b) Micropipette visual tracking results. Due to the induced mechanical vibration in Case2, the tracking algorithm fails to locate the mciropipette.

Figure 2.8: Micropipette controller. (a) Three cases of PID gains and implemented gain scheduling. (b) The visual tracking results of the cases. Despite the fast response in Case2, the induced vibration compromises the visual tracking performance. Thus, a slower set of gains (Case1) is chosen to provide a smooth, vibration-free motion at the micropipette tip. 


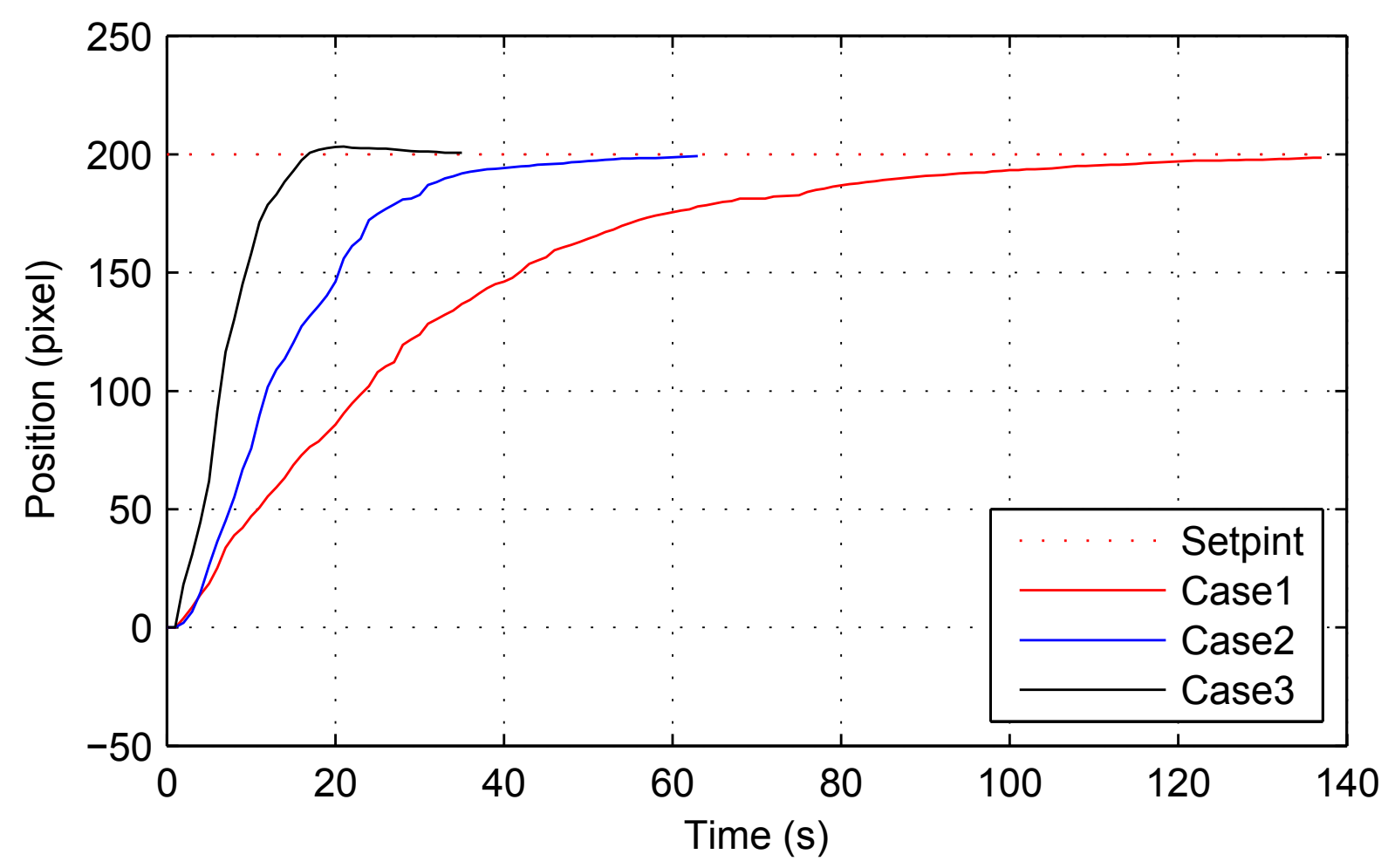

Figure 2.9: XY stage response to a step input of 200 pixel in X-axis. Case1 is overdamped, Case2 is critically damped, and Case3 is slightly underdamped.

to the stage amplifier via a COM port (Fig. 2.9).

\subsection{Micropipette Fabrication}

Micropipettes were made from borosilicate glass tubes with $\mathrm{OD}^{1}$ of $1.0 \mathrm{~mm}$ and $\mathrm{ID}^{2}$ of $0.75 \mathrm{~mm}$ (Sutter Instrument). Each glass pipette was first pulled using a micropipette puller (Sutter Instrument). Following that, the tips were fractured to create an inner diameter of 2 to $5 \mu \mathrm{m}$ using a micro-forge (Technical Products International, Inc.). The tip of the micropipettes were then bent $45^{\circ}$ using the micro-forge. This bend aligns the micropipette tip with the microscope glass slide preventing perspective errors in imaging.

${ }^{1}$ Outer diameter (OD)

${ }^{2}$ Inner diameter (ID) 


\section{Chapter 3}

\section{Software Design}

\subsection{Introduction}

The automation process is designed and implemented in LabVIEW (National Instruments). The hardware interfaces (Fig. 2.2) with the PC using National Instrument boards (NI PICe-6259). The automation of micropipette aspiration involves multiple accurately timed hardware interactions that call for a robust system design and implementation. To achieve this, the automation process was broken down into simple tasks (explained thoroughly in Chapter 4.2). To execute the sequence, a task management system was developed that logs and handles errors preventing any damage to the hardware and cell samples.

\subsection{Image Processing}

Some of the prescribed tasks (Chapter 4.2) involve image processing such as: (1) tracking the micropipette tip that is to be positioned in the proximity of the cell; $(2)$ tracking the cell on which aspiration will be performed; (3) tracking the deformation of the cell into the micropieptte opening that is induced by vacuum pressure. 


\subsubsection{Micropipette Tracking}

The micropipette tip is visually tracked using an optimized rotation-invariant normalized cross-correlation (NCC) method. The basic NCC algorithm was described in [48]. A template of the micropipette tip (Fig. 3.1(a)) is cross-correlated with the current frame of the image to locate the best match within a search area. The selection of a template is required only when a new micropipette is mounted on the micromanipulator at the beginning of an experiment. Once the template is selected, the search area is limited to close proximity of the last known location of the micropipette from the previous frame. This method reduces the search time. The normalized cross-correlation algorithm determines the location and the angle of the matched template $(x, y, \alpha)$, as shown in Fig. 3.1(c).

\subsubsection{Cell Tracking}

There are typically several cells present within a field of view. Thus, the cell tracking algorithm requires the user to indicate which cell is the target for characterization via one computer mouse click anywhere on top of the target cell (see green cross in Fig. 3.2(a)). The cell tracking algorithm uses binary morphology techniques [49] to determine the position of the cell. The system then forms a region of interest (ROI) that is binarized with the Otsu adaptive thresholding method (Fig. 3.2(b)). Close binary operation is used to create a smooth object on the outside (Fig. 3.2(c). Convex hull is used to obtain the cell's envelope (Fig. 3.2(d)), and objects with small areas are removed (Fig. 3.2(e)). The system determines the position and radius of the cell, $\left(x, y, R_{c}\right)$ (Fig. 3.2(f)) using least squares fitting. 


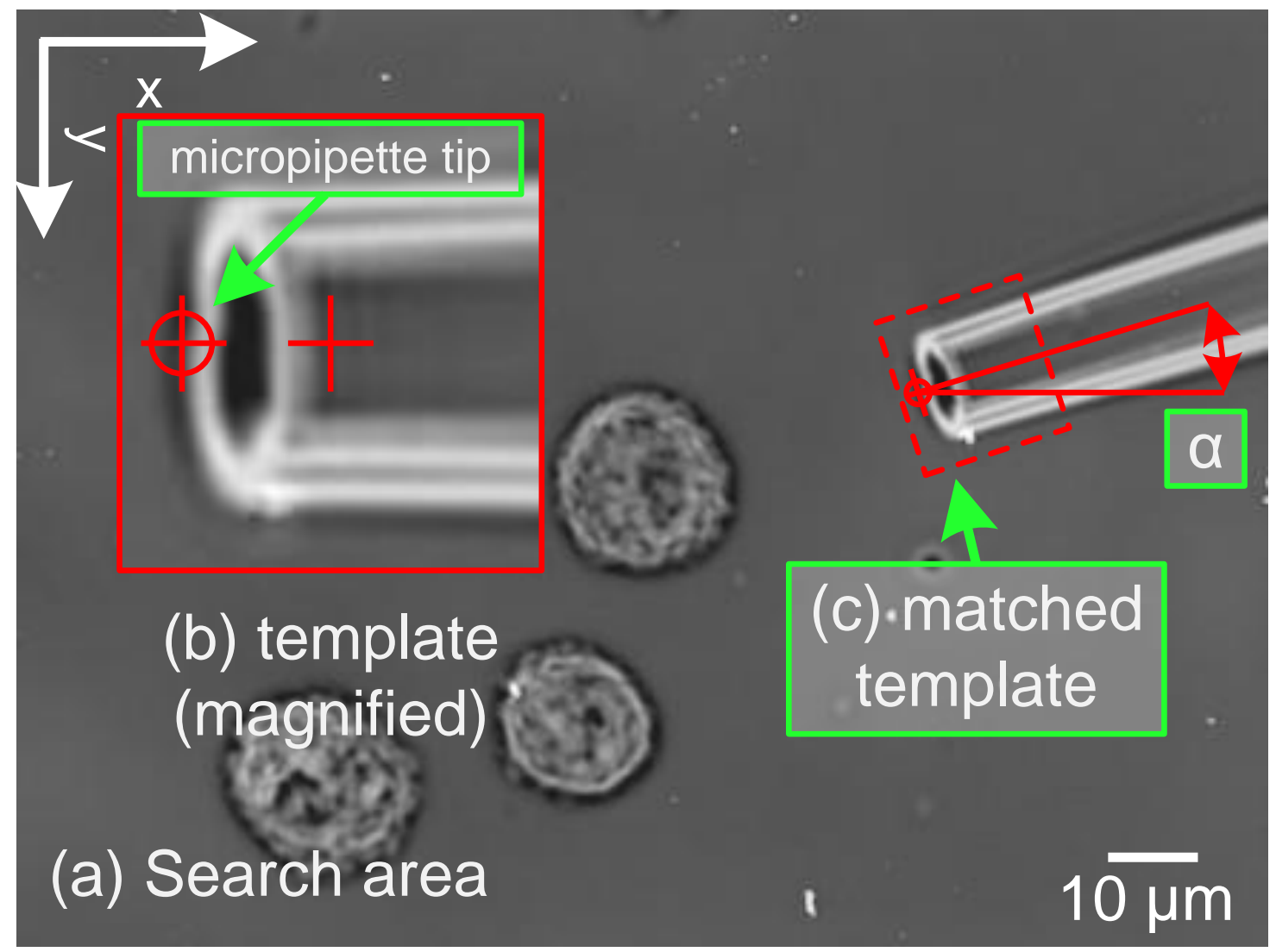

Figure 3.1: Micropipette tracking. (a) Search with the normalized cross-correlation algorithm within the search area. (b) User selects a template containing the micropipette tip. (c) Matched template location and angle $(x, y, \alpha)$.

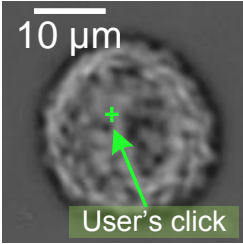

(a) $\mathrm{ROI}$

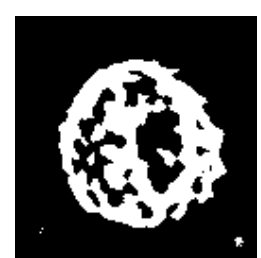

(b) Threshold

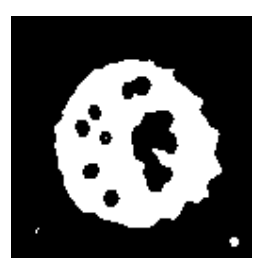

(c) Close

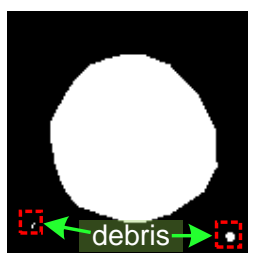

(d) Convex

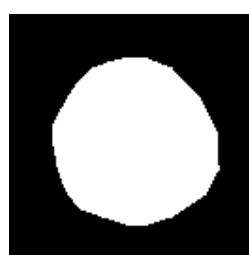

(e) Filtered

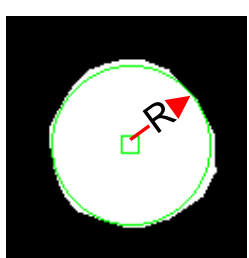

(f) Circle fitting

Figure 3.2: Cell tracking. (a) ROI formed around user's click (green cross). (b) Binarized image with the Otsu adaptive thresholding method. (c) Morphological close operation creates a smooth object. (d) Morphological convex operation fills the holes and create an envelope of the cell. (e) Noise removal based on object area. (f) Least square fitting to obtain a circle $\left(x, y, R_{c}\right)$. 


\subsubsection{Aspiration Length Tracking}

When a cell is aspirated into the micropipette, a ROI is formed to include the inside of the micropipette, as shown in Fig. 3.3(a). The extracted ROI is then convolved with a standard $5 \times 5$ West Sobel kernel to eliminate the vertical edges and enhance the horizontal contours (Fig. 3.3(b). The result of the gradient filter is binarized using the Otsu method, as shown in Fig. 3.3(c). After binary morphology, the objects found in the image are filtered according to two criteria: (1) object is removed if the area is smaller than a threshold value; and (2) object is removed if the center of mass is not in the 'safe' zone (within the micropipette), as shown in Fig. 3.3(c). The first criterion filters out noise and small background debris. The second criterion ensures that the attached debris to the wall of the micropipette is not recognized as part of the cell contour. The left most object is recognized as the protruded cell contour (see green line in Fig. 3.3(c)).

\subsection{Data Handling}

In the automated process the data is analyzed once experiments are completed, so data is stored during experiments and is retrieved in the last step to calculate the mechanical properties. The data storage and retrieval is done using National Instrument technical data management $\left(\mathrm{NI} \mathrm{TDM}^{1}\right)$ technology. The NI TDM solution is a fast method to stream large amounts of structured data to and from the hard drives which suits this project application. During each experiment, the following are stored: (1) time stamp in milliseconds; (2) current pressure in Pa; (3) measured aspiration length; (4) snapshot of the cell before it is aspirated; and (5) a video of the whole process.

\footnotetext{
${ }^{1}$ More information is available at http://www.ni.com/white-paper/3539/en
} 

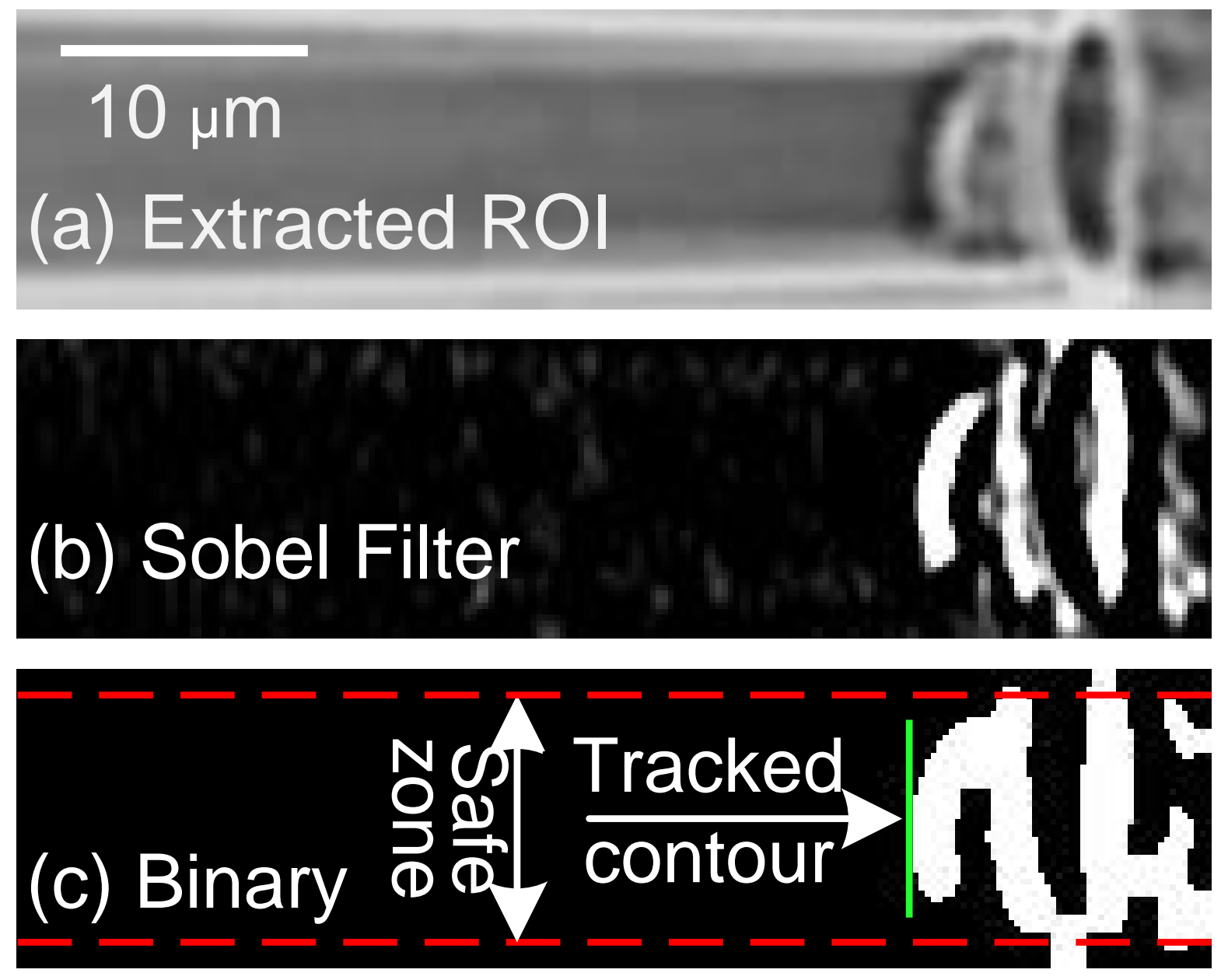

Figure 3.3: Cell aspiration length tracking. (a) ROI containing the inside of the micropipette. (b) Sobel filter is used to enhance the edges and remove vertical edges. (c) The tracked aspiration length is highlighted in green, and the area between the dashed red lines is termed 'safe zone'. 


\subsection{Software Operation}

The LabVIEW graphical user interface (GUI) of the automation software is presented in Fig. 3.4. This section describes the system setup and configuration.

The implemented GUI in LabVIEW is presented in Fig. 3.4. The top-left part allows the user to run the software in auto mode and manual. In auto mode, all tasks are queued and run sequentially. In case an error occurs, the system exits the auto mode and displays error messages as a log in the GUI. In the manual mode, the user decides the sequence of the tasks. This mode is suitable when new testing protocols are being developed or the user is debugging the system. The user can select among three types of experiments: elastic, viscoelastic or viscose. The settings for each task could be defined in system settings part Fig. 3.5. The attached hardware could be controlled using the bottom-left part of the GUI (Fig. 3.6). The bottom-right corner of the GUI shows a live output of the measured parameter during the experiments. The live overlayed feed from the camera is displayed in the top-left part of the GUI. 


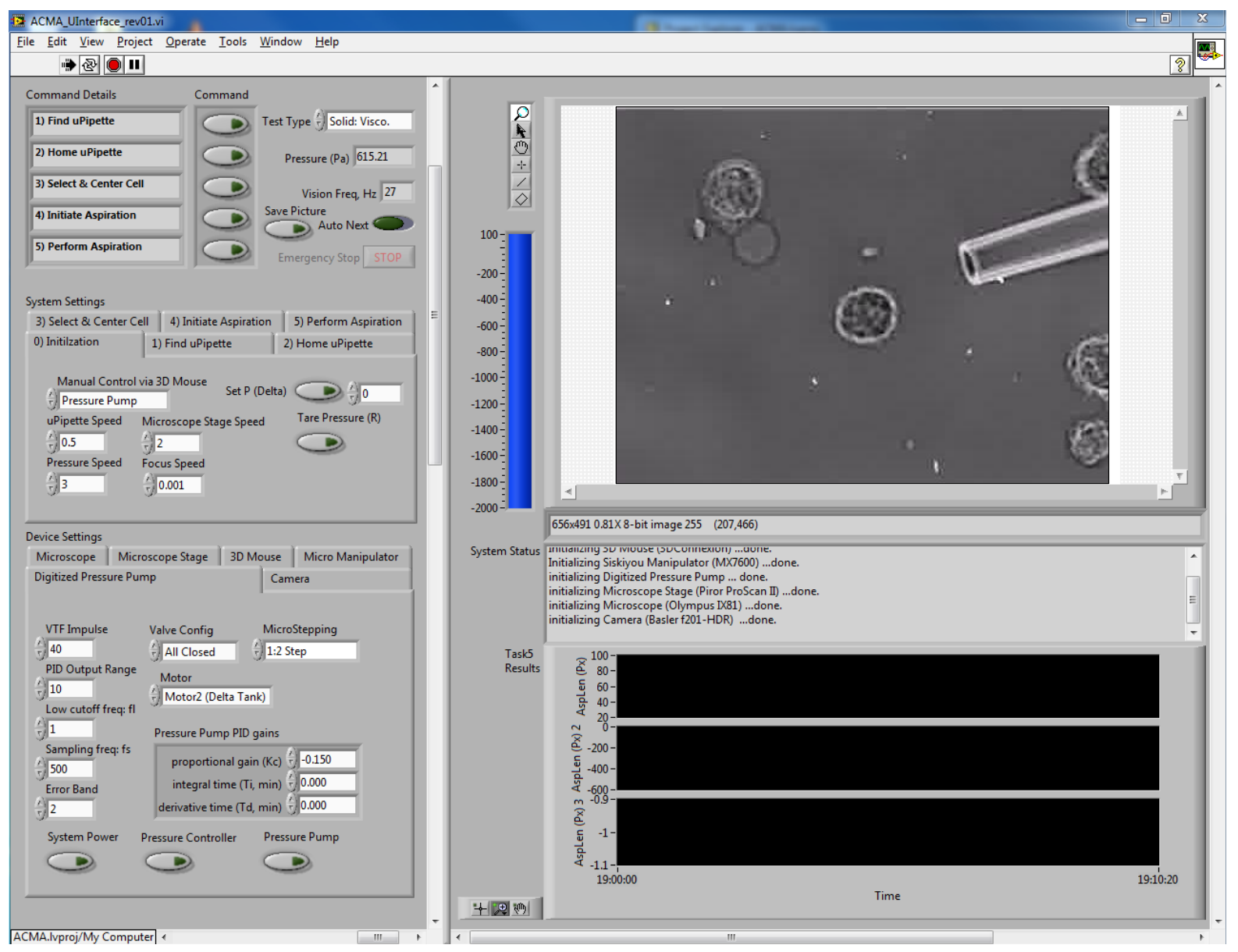

Figure 3.4: Automated micropipette aspiratation GUI. Commands (tasks) that are executed in order. Test type determines the experiment (elastic, viscoelastic, or viscose). System settings are the settings for each individual command (task). Device settings are the setup parameters for the hardware connected to the PC. The top-right corner presents a live video of the cell under experiment. The bottom-right graphs present realtime measurements of aspiration length, applied pressure, and cell radius. Between the live video and graphs, the system logs all the activities including errors. 


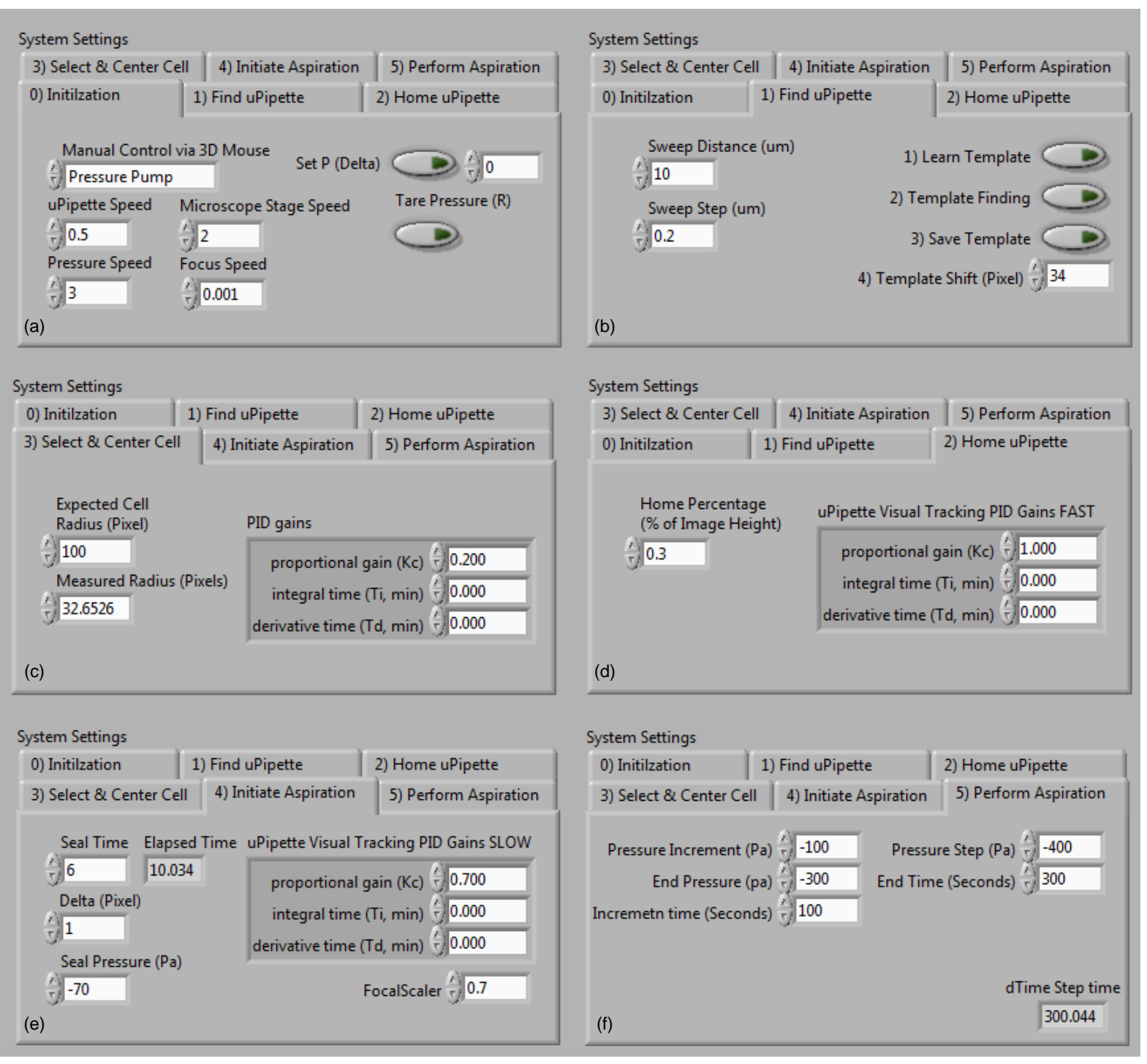

Figure 3.5: System settings. (a) Allows the user to select the setup of the experiment before starting the automated process. This section grants the user access to all the connected hardware via $3 D$ mouse. (b) Settings for finding the template in the focal axis of the microscope. This section contains the settings for the depth of sweep, and template definition. (c) Settings for centering the cell in the image. This section contains PID gain parameters for XY stage, expected cell radius and measured cell radius. (d) Settings for homing micropipette. This section contains the micromanipulator PID gain parameters, and relative position of the "home" as a percentage of the image height. (e) These settings define the seal making parameters. In particular, the PID gain parameters for the micromanipulator are set to create a slow movement of the tip to prevent disturbance. (f) These are the experiment parameters such as the interval between pressure decreases and the step size. 


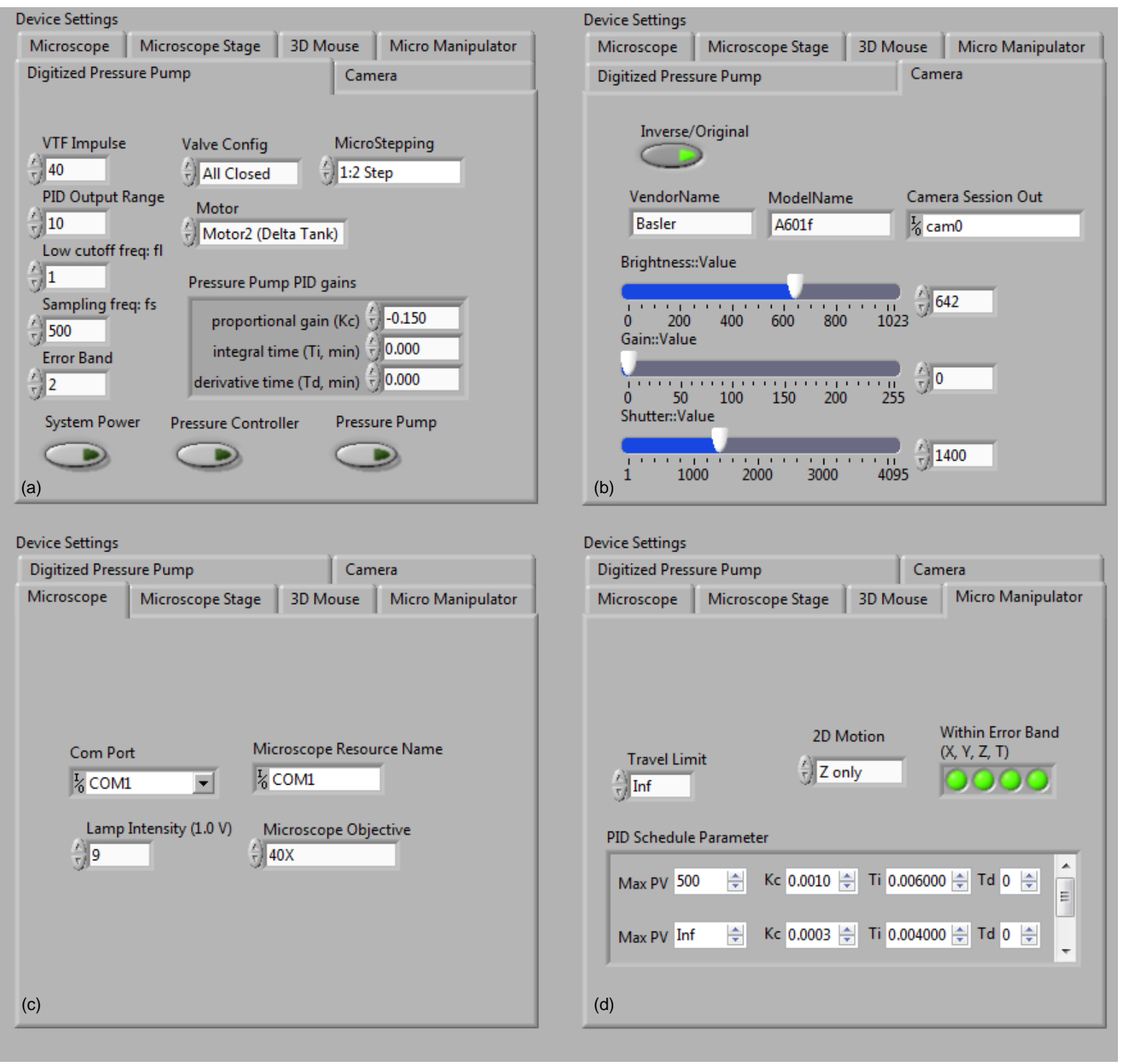

Figure 3.6: Device settings. (a) These settings adjust the PID loop of the custom-built pressure pump such as PID gain parameters, voltage-to-frequency converter, low-pass filter, and error band. (b) Settings for the camera such as the name, brightness, contrast, and shutter values. (c) The settings for microscope such as the light intensity level, magnification, and communication port. (d) These settings are for the inner-loop of the micromanipulator which works based on gain scheduling. 


\section{Chapter 4}

\section{Validation Experiments}

The automated system was used to perform experiments on porcine aortic valve interstitial cells (PAVICs) and human promyelocytic leukemia cells (HL-60). These cell types were previously tested with manual micropipette aspiration technique and their mechanical properties were reported in literature $[32,43,51]$. In the validation process, the mechanical properties of these cells were calculated using the previously developed mathematical models. This ensures the validity of the developed automated setup, so the system could be used for performing automated micropipette aspiration on other types of cells (Chapter 5).

\subsection{Sample Preparations}

The PAVICs used in the experiments were harvested from aortic valve leaflets from month old hog hearts which were provided by an abattoir. Each leaflet was rinsed with antibiotic and then treated with collagenase $\left(150 \mathrm{U} / \mathrm{mL}, 37^{\circ} \mathrm{C}\right)$. The leaflet surfaces were scraped to remove endothelial cells. The leaflets were digested with collagease (150 $\mathrm{U} / \mathrm{mL}, 37^{\circ} \mathrm{C}, 2$ hours), once they were minced. The supernatant was then strained, centrifuged and resuspended in standard tissue culture medium (DMEM supplemented with $10 \%$ FBS and $1 \%$ antibiotics). The cells were then plated on tissue culture flasks 
and were placed in an incubator. The cells were fed every two days using supplemented DMEM. Once the cultured cells were confluent, the cells were resuspended in standard DMEM using the trypsinization method.

The HL-60 used in the experiments were obtained by leukopheresis from a 36-year-old female with acute promyelocytic leukemia (ATCC CCL-240). The cells were subcultured by replacement of medium (as recommended by ATCC) every 2 days.

\subsection{Experimental Protocols}

The system performs cell aspiration according to the following protocol consisting of five steps (Fig. 4.2): (1) find and home micropipette based on a pre-defined micropipette template; (2) center a user-selected cell in the field of view; (3) create a seal between cell and micropipette tip based on a pre-defined pressure, $P_{\text {seal }}$; (4) perform aspiration; and (5) process data.

Since we are interested in visually tracking the deformation of the cells inside the glass micropipette, it is important that the focal plane is set on the axis of the micropipette in every test. Thus in task 1 (Fig. 4.2(a)), the microscope focal plane is swept to find an accurate focal plane that passes through the micropipette axis. The template is defined at the focal plane from which the axis passed. In this task, the micropipette is moved to the upper-right corner of the image to prevent collision with cells and the creation of disturbance flows around the cells while the operator is moving the XY stage to find a cell to test (Fig. 4.1(b)).

Upon finding a cell to test, the operator clicks on top of the cell to initiate task 2 (Fig. 4.2(b)). In this task, the cell is located and positioned in the center of the image (Fig. 4.1(b) to (c)). The radius of the cell is measured, which will be used in task 3 .

Once the cell is centered, the micropipette is moved slowly to the proximity of the cell which is defined based on the cell radius (Fig. 4.1(d)). Following that, seal pressure $\left(P_{\text {seal }}\right)$ 
is applied that causes the cell to move towards the micropipette opening (Fig. 4.1(e)) and creates a seal. After 10s (cell response time), the micropipette and the focal plane are moved up by twice the radius of the cell that ensures cell suspension in the sample media. This process (Fig. $4.2(\mathrm{c})$ ) is very tedious to be done manually since it requires the operator to synchronize multiple hardware components in a short period of time (approximately 6 seconds).

There are three types of experiments that a user can choose to conduct in task 4 (Fig. 4.2(d)): (a) characterization of elastic properties of solid-like cells; (b) characterization of viscoelastic properties for solid-like cells; (c) viscous properties of liquid-like cells. The results of the test are streamed using NI TDM in this task.

Once the tests are perfomed, the system calculates the desired mechanical properties based on the selected experiemts in task 5 (Fig. 4.2(e))

In our experiments, the system was used to measure the elastic and viscoelastic properties of PAVICs. It has been shown that the mechanical properties of aortic valves play an important role in the heart's functionality [50,51]. The regulatory valve function is also affected by the valve cells. Hence, this system was used to test the mechanical properties of the PAVICs to demonstrate how an automated system can help investigate the aortic valve mechanics at the cellular level.

For testing liquid-like cells, HL-60 cells were used for viscosity characterization. Leukocytes are known to play a significant role in blood flow and oxygen delivery in microcapillaries. Less deformable cells induce impairment to the circulation of the eye and the central nervous system causing damage to these organs [52]. Since HL-60 shares similar characteristics with promyeloblasts and promyelocytes, it has been used as a model for investigating the cellular deformability of the leukocytes. 


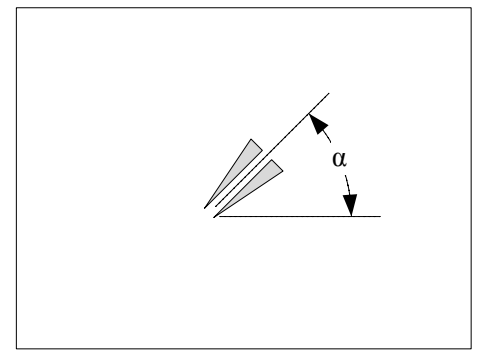

(a)

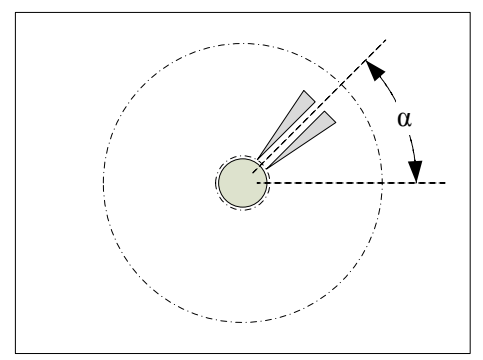

(d)

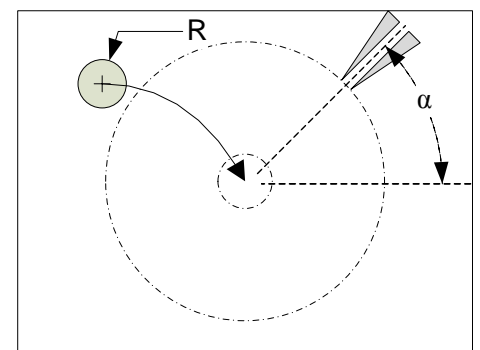

(b)

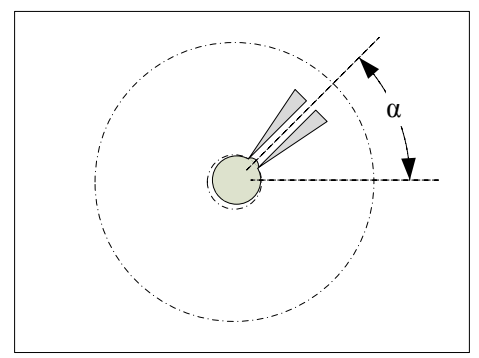

(e)

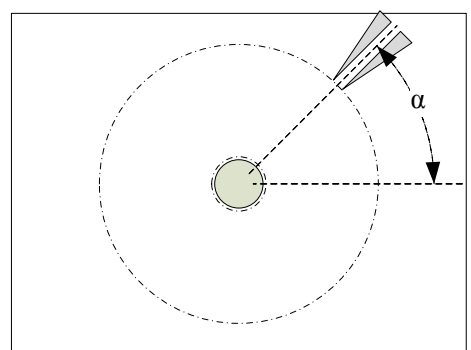

(c)

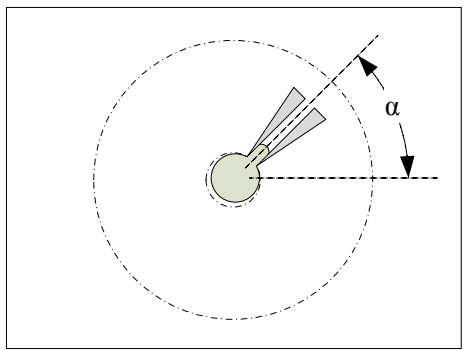

(f)

Figure 4.1: Automated micropipette aspiration process. (a) Locating the micropipette tip using the pre-defined template. (b) Moving the micropipette to the top-right corner and centering the selcted cell to the center of the image. Micropipette is located such that its axis passes through the center of the image (cell). (c)-(d) The micropipette moves to the proximity of the cell slowly without touching the cell. (e) The seal pressure $P_{\text {seal }}$ causes the cell to move towards the tip and creating a seal between the micropipette tip and the cell. (f) Induced pressure causes the cell to deform into the micropipette and the imaging system captures the aspiration length during the experiment. 


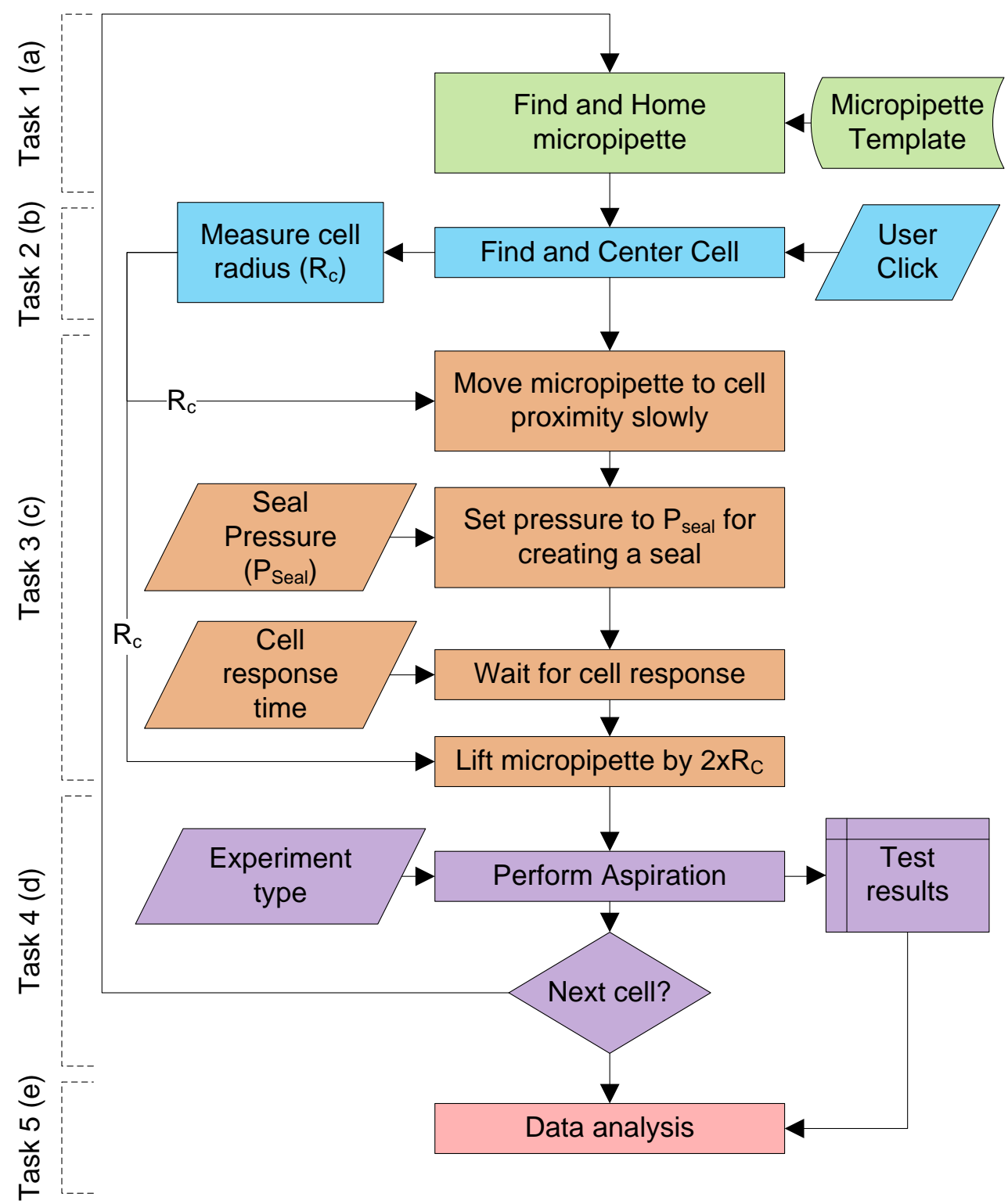

Figure 4.2: Automated micropipette aspiration flow chart. (a) Task 1 finds and parks the micropipette in home position. (b) Task 2 selects a target cell. (c) Task 3 creates a seal between the mouth of the micropipette and the cell. (d) Task 4 generates a specific pressure profile based on the experiment type. (e) Task 5 performs data analysis and calculates biomechanical properties of the tested cell. 


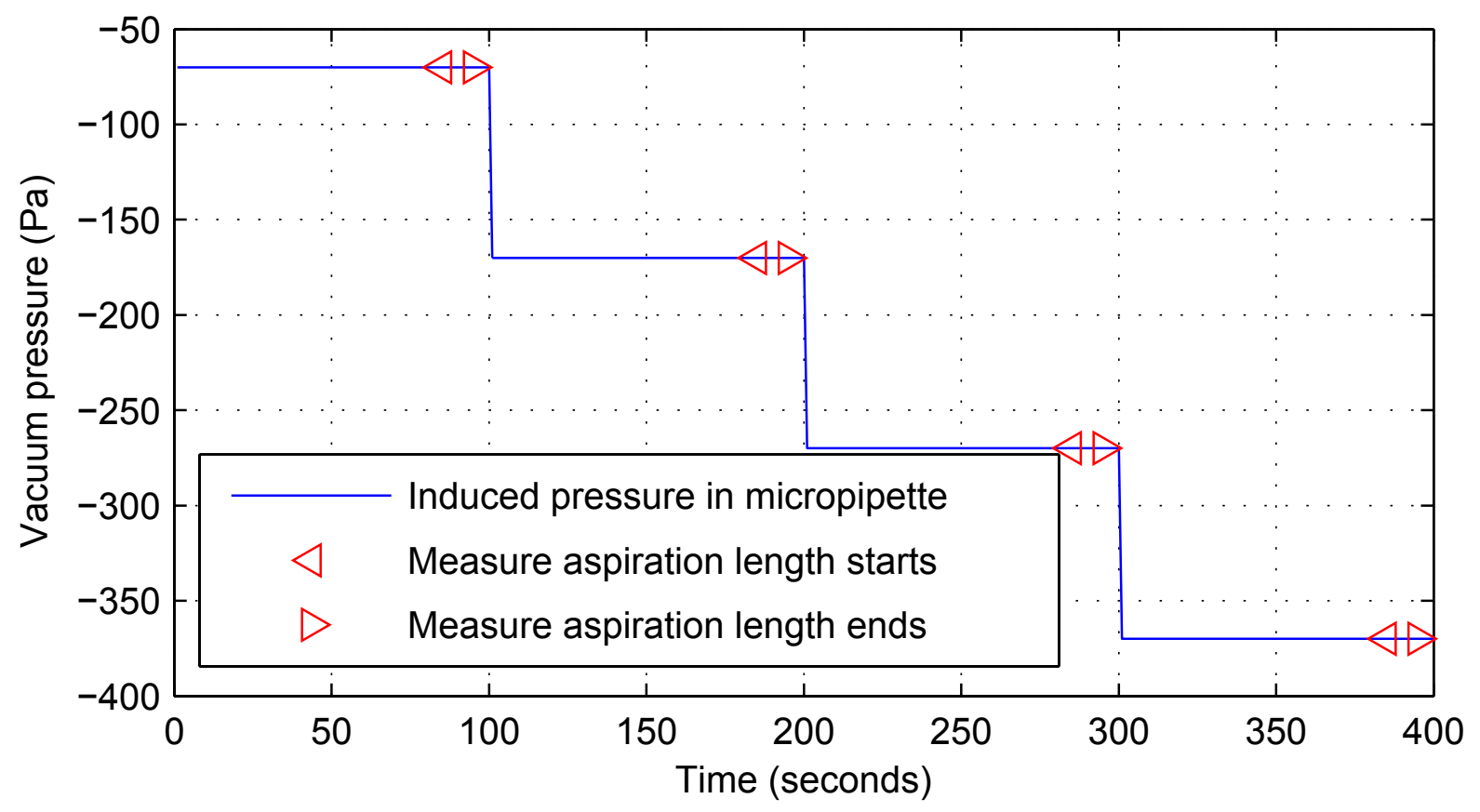

Figure 4.3: Pressure profile used to test PAVICs. A $-70 \mathrm{~Pa}$ was used to make a seal between the cell and the micropipette tip. After an interval of 100 seconds, the pressure was decreased by $100 \mathrm{~Pa}$. The aspiration length is averaged for 10 seconds at the very end of each interval representing the deformation in that pressure level.

\subsection{Elastic Characterization}

In order to measure the Young's modulus of the cells, the system applied a series of small pressure steps (4 steps of $-100 \mathrm{~Pa}$ ) to the cell with an interval of 100 seconds via the digital pressure system with an initial seal pressure of $-70 \mathrm{~Pa}$ (Fig. 4.3). The aspiration length $(L)$ and step pressure $(\Delta P)$ are related by the half space model [31]

$$
\frac{L}{R_{p}}=\frac{3 \Delta P}{2 \pi E} \Phi_{p}(\eta)
$$

where $E$ is the Young's modulus, $\Phi_{p}$ for our used micropipette is approximately 2.1, and $\eta$ is the wall parameter. The aspiration length, $L$ and suction pressure, $\Delta P$ (Fig. 4.4(a)) at the end of each 100-second interval were used for linear regression to obtain the Young's modulus from the slope of the fitted line. A robust linear regression was used to eliminate the effect of outliers. The determined Young's modulus value for the tested 
PAVICs is $358.7 \pm 192.1 \mathrm{~Pa}(\mathrm{n}=30)$. This result is in agreement with our previous results $(354.8 \pm 142.0 \mathrm{~Pa})$ from manual testing [43] and the results reported in [51].

\subsection{Viscoelastic Characterization}

We also used the system for quantifying viscoelastic properties of PAVICs. In viscoelastic characterization, the system applied to the cell a large step pressure (-400 Pa) for 150 seconds. In this period, the system on-line measured the cell aspiration length, $L(t)$, which is related to step pressure input $(h)$ by the Kelvin model [32]

$$
L(t)=L_{s}\left[1-\frac{k_{2}}{k_{1}+k_{2}} \exp \left(\frac{-t}{\tau}\right)\right] h(t)
$$

where $L_{s}$ is the aspiration length at the end of the interval (Fig. 4.3)

$$
L_{s}=\lim _{t \rightarrow \infty} L(t)=\frac{2 R_{p} \Delta P}{\pi k_{1}}
$$

and $h(t)$ is a unit step function

$$
h(t)= \begin{cases}1 & \text { if } t \geq 0 \\ 0 & \text { if } t<0\end{cases}
$$

$k_{1}$ and $k_{2}$ are the elastic constants of a standard linear body and $\tau$ is the time constant given by

$$
\tau=\frac{\mu}{k_{1}}\left(1+\frac{k_{1}}{k_{2}}\right)
$$

Using least-squares nonlinear fitting, $L(t)$ was fitted to the recorded data to determine $k_{1}, k_{2}$, and $\tau$ (Fig. 4.4(b)), where $k_{1}$ and $k_{2}$ are the elastic constants of a standard linear body, and $\tau$ is the time constant. The results are summarized in Table 4.1 together with the previously reported values from manual testing [32]. 
Table 4.1: Determined viscoelastic parameters of PAVICs

\begin{tabular}{lccc}
\hline Viscoelastic Parameters & $k_{1}$ & $k_{2}$ & $\tau$ \\
\hline Automated MA results $(n=25)$ & $190 \pm 70$ & $270 \pm 70$ & $40 \pm 30$ \\
Literature reported values [32] & $150 \pm 60$ & $310 \pm 70$ & $45 \pm 11$ \\
\hline
\end{tabular}

\subsection{Viscosity Characterization}

To quantify the viscosity of liquid-like cells, the automated micropipette aspiration system applied step pressures ranging from -700 Pa to -220 Pa for 150 seconds to HL-60 cells. In this period, the system automatically measured aspiration lengths, $L(t)$, as shown in Fig. 4.5. Using a power-law fluid model $[52,53]$, the shear rate dependence of cytoplasmic viscosity is formulated in Eqn. 4.6 where $\mu_{c}$ is the characteristic viscosity (unknown variable) at the characteristic shear rate $\gamma_{c}$, and $b$ is a material coefficient.

In order to measure the the characteristic viscosity $\left(\mu_{c}\right)$, a series of experiments have been performed at various hydraulic suction pressures $\left(\Delta P_{h}\right)$ ranging from $-700 \mathrm{~Pa}$ to $-220 \mathrm{~Pa}$. In each experiment, the cytoplasmic viscosity $(\mu)$ and characteristic shear rate $\left(\gamma_{c}\right)$ are measured using Eqn. 4.7 and Eqn. 4.15, respectively. Following that, cytoplasmic viscosities at various hydraulic suction pressures have been fitted to the power-law model represented by Eqn. 4.6 to measure the characteristic viscosity of HL-60 cells (Fig. 4.5(b)).

$$
\mu=\mu_{c}\left(\gamma_{m} / \gamma_{c}\right)^{-b}
$$

where $\mu$ is the cytoplasmic viscosity and is denied as

$$
\mu=\frac{\Delta P_{h} t_{e}}{4\left(a_{0}+a_{1} r+a_{2} r^{2}+a_{3} r^{3}\right) \sqrt{r^{2}-1}}
$$


where coefficients $a_{i}(i=0,1,2,3)$ are defined as

$$
\begin{aligned}
& a_{0}=-1.3079-0.019975 \beta+0.13869 \beta^{2}-0.87898 \beta^{3} \\
& a_{1}=2.0756-0.21461 \beta+0.065414 \beta^{2}+2.0469 \beta^{3} \\
& a_{2}=-0.37513-0.10393 \beta-0.4992 \beta^{2}-1.6295 \beta^{3} \\
& a_{3}=0.38012+0.29926 \beta+0.28995 \beta^{2}+0.45455 \beta^{3}
\end{aligned}
$$

and $r$ is defined as

$$
r=R_{0} / R_{p}
$$

where $R_{p}$ is the micropipette radius, and $\beta$ is proportional to the ratio of the threshold pressure to the hydrostatic aspiration pressure and defined as

$$
\beta=\frac{2 T / R_{p}}{\Delta P_{h}}
$$

where $T$ is the cortical tension and according to [40] the average $T$

$$
T=3.5 \times 10^{-5} \mathrm{~N} / \mathrm{m}
$$

$\gamma_{m}$ is the mean shear rate during cell entry into the micropipette and is defined as

$$
\gamma_{m}=\frac{\Delta P_{h}}{4 \mu} \frac{b_{0}+b_{1} r+b_{2} r^{2}+b_{3} r^{3}}{\left(r^{2}-1\right)^{7 / 20}}
$$

where coefficients $b_{i}(i=0,1,2,3)$ are defined as 


$$
\begin{aligned}
& b_{0}=8.8685+1.8690 \beta \\
& b_{1}=-4.4846-2.7003 \beta \\
& b_{2}=1.0322+0.9222 \beta \\
& b_{3}=-0.09117-0.1027 \beta
\end{aligned}
$$

In this study, $\gamma_{c}$ was set to $1 \mathrm{~s}^{-1}$. Characterization results are $\mu_{c}=171.35 \pm$ 13.042 Pa.s, and $b=0.78 \pm 0.08$ for HL-60 cells $(n=30)$. These values are in agreement of the previously reported value [52]. 


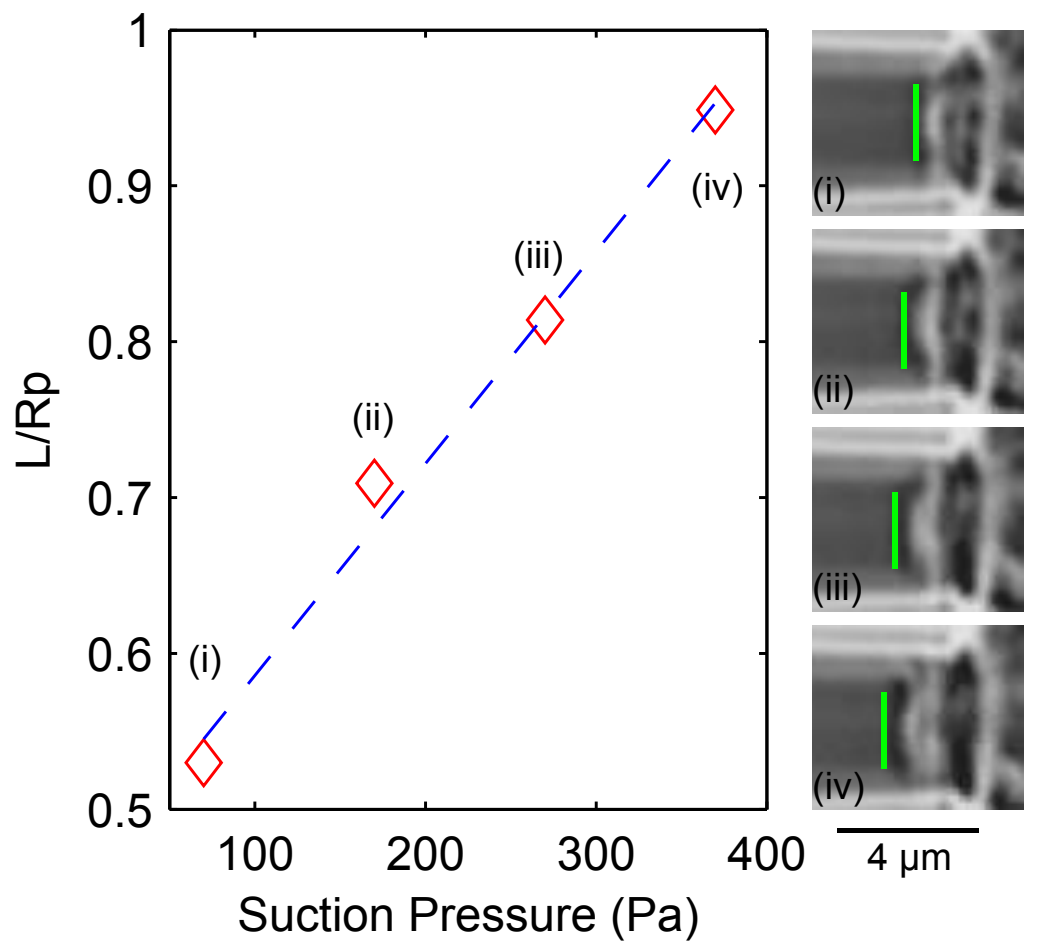

(a) Elastic response

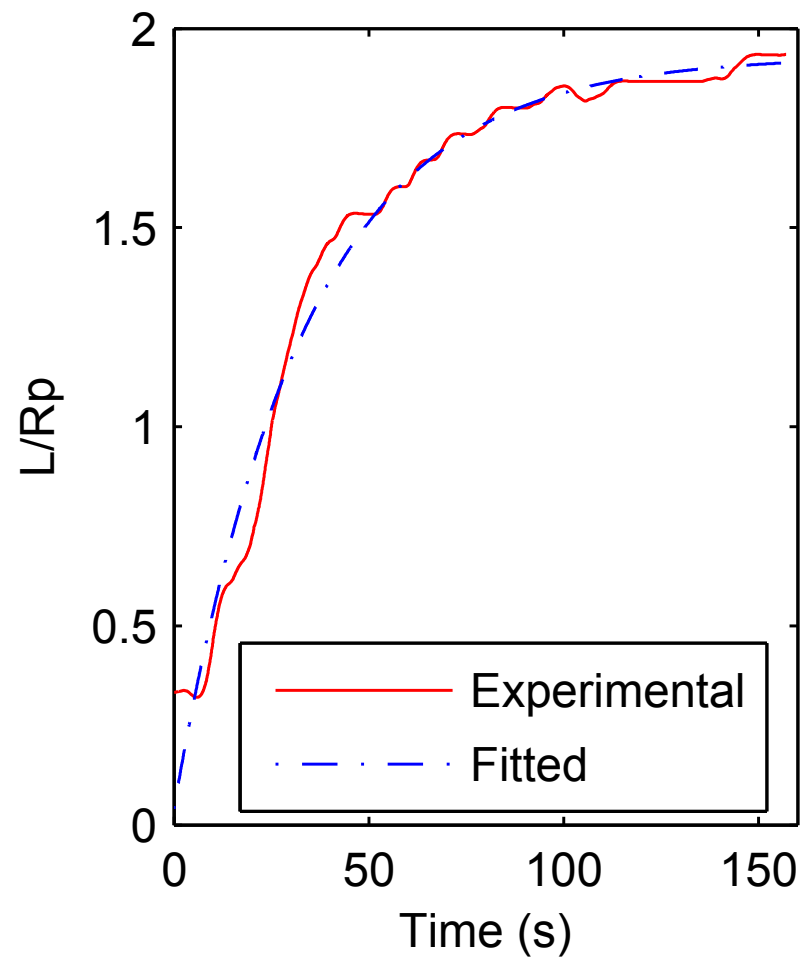

(b) Viscoelastic response

Figure 4.4: Elastic and viscoelastic responses of PAVICs. $L$ is the aspiration length and $R_{p}$ is the radius of the micropipette. (a) Elastic response of a PAVIC, where (i)-(iv) are equilibrium points at the end of 100-second intervals. (b) Viscoelastic response of a PAVIC. A step pressure of $-400 \mathrm{~Pa}$ was applied for 150 seconds. 

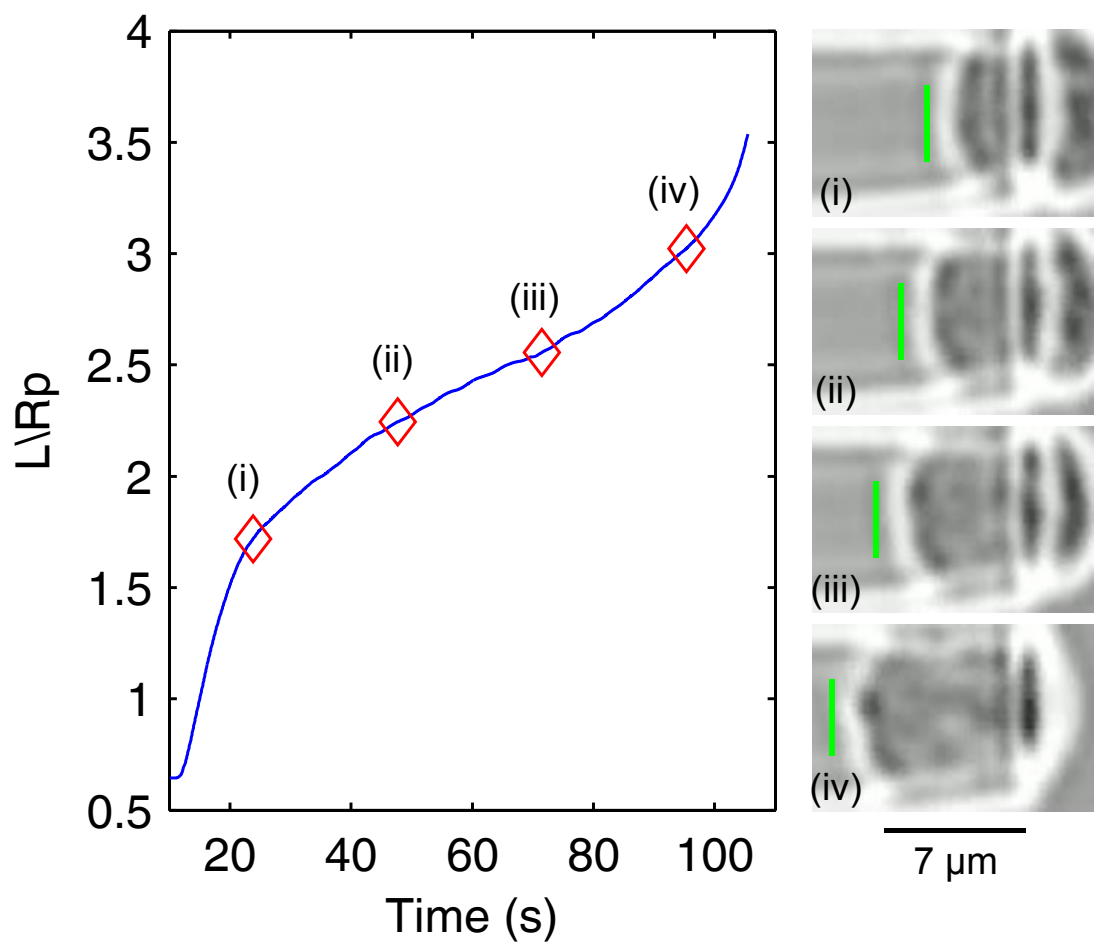

(ii)

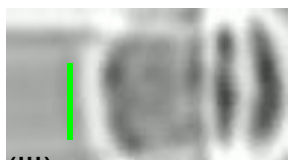

(iii)

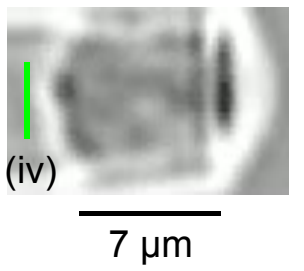

(a) Viscous response

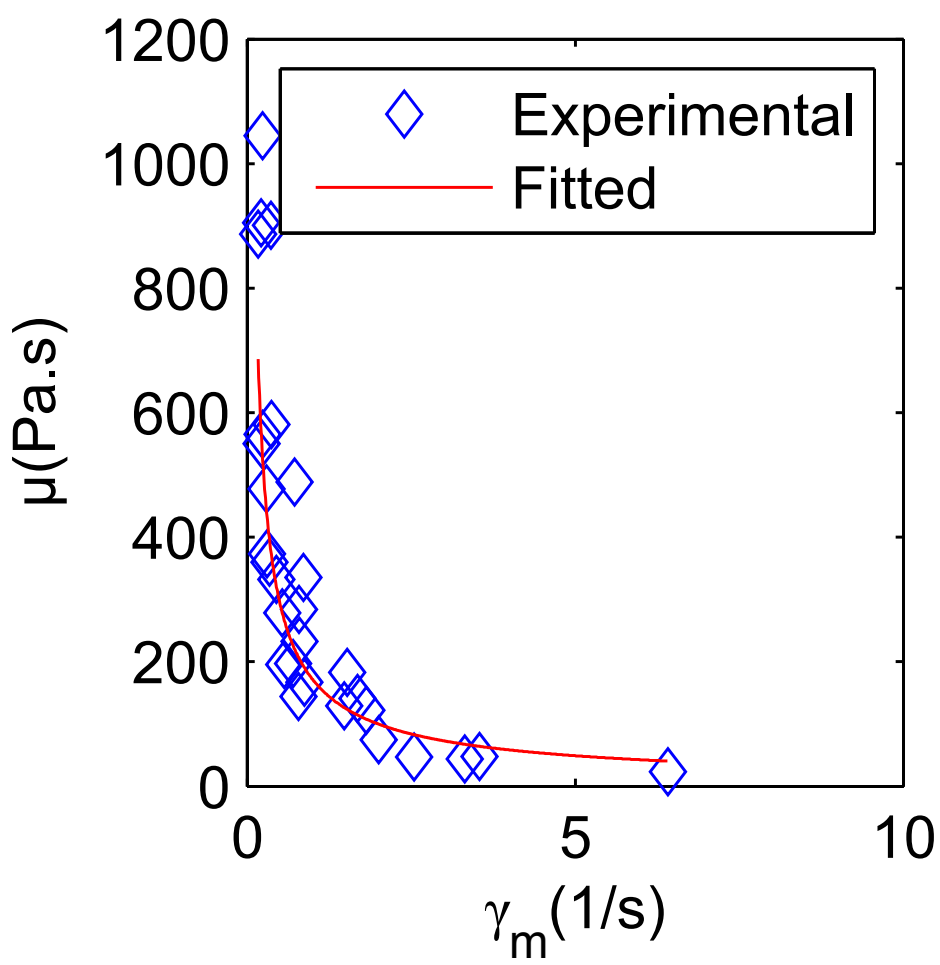

(b) Cytoplasmic viscosity

Figure 4.5: Viscous properties of HL-60 cells. (a) Viscous response of an HL-60 cell to a step pressure of $-270 \mathrm{~Pa}$. (i)-(iv) show the cell at various time instances. $L$ is the aspiration length and $R_{p}$ is the radius of the micropipette. (b) Cytoplasmic viscosity as a function of mean shear rate $\gamma_{m}$. Step pressure varied from $-700 \mathrm{~Pa}$ to $-220 \mathrm{~Pa}(n=30)$. 


\section{Chapter 5}

\section{Voided Urine Study}

\section{$5.1 \quad$ Introduction}

Bladder cancer is the most common tumor of the urinary system in North America, representing the $4^{\text {th }}$ most common malignancy in men and the $10^{\text {th }}$ most common in women [54]. More than 350,000 individuals are diagnosed with bladder cancer per year worldwide, including more than 70,000 per year in the United States [55]. Urothelial carcinomas (UCs) or transitional cell carcinoma (normal cells from the lining of bladder undergo changes that lead to the uncontrolled cell growth characteristic of cancer) is by far the most common type of bladder cancer ( $90 \%$ ) in the United States [56]. 70\% of UCs recur, and $10-30 \%$ of recurrent UCs progress to invasive cancer, necessitating lifelong monitoring of patients [57].

Cystoscopy is the golden standard for detection of urothelial carcinoma, but it is invasive and causes significant patient discomfort, especially for patients who need periodic monitoring $[58,59]$. Over the past decade, a considerable amount of effort have been devoted to the development of biochemical and genetic markers for non-invasive bladder cancer detection on voided urine. However, the demand for highly trained medical staff along with the cost of DNA probes and biochemical markers still limit the application of 
these methods for patients with lifelong monitoring requirement.

Urinary cytology, which evaluates urothelial cells present in voided urine exfoliated from the lining of the urinary tract, is a convenient noninvasive and relatively inexpensive technique for follow-up analysis of patients treated for urinary tract cancers over a period of time [60]. Though urinary cytology has high specificity and relatively high sensitivity for the detection of UC, its overall usefulness is limited by the fact that it is solely based on the morphology of the cells, the morphological overlap can sometimes interfere with the interpretation. Consequently its accuracy is highly operator dependent requiring the experience of cytologists $[60,61]$.

The past decade has witnessed a substantial growth of research on the biomechanical property changes of cancerous cells, compared with their healthy counterparts $[6,8]$. Briefly, the cytoskeleton proteins within a cell's membrane constitute an internal scaffold, which determines the shape and mechanical properties of the cell. Cancer cells reprogram their growth, division and mobility by modifying proteins and their interaction, including the cytoskeleton [62]. A number of studies have proven that changes of mechanical properties are crucial for cancerous cell to alter their gene expression and invade the circulation system [6]. Thus the mechanical property of cells can potentially serve as a mechanical maker for cancer detection.

In this chapter, we explore the feasibility of mechanical properties for assisting urinary cytology on cancerous urothelial cell distinguishing. All cells were obtained from voided urine of urothelial carcinoma negative and positive donors, the Young's modulus was measured using an automated pipette aspiration system [29]. The preliminary results revealed that the mechanical marker (Young's modulus) can improve urinary cytological judgment and can potentially be applied to non-invasive urothelial carcinoma monitoring. 


\subsection{Materials and Methods}

\subsubsection{Urine Preparation and Cell Selection}

Details on the working mechanism and operation procedure of the pipette aspiration system are given in Chapters 2 to 4 . Samples from healthy donors, $200 \mathrm{~mL}$ of voided urine were collected and divided into four $50 \mathrm{~mL}$ centrifugal tubes (due to the extremely low cell density in the voided urine of healthy donors ( $<150$ cells per $200 \mathrm{~mL})$, a large volume of urine was collected). Samples were then centrifuged at $400 \mathrm{~g}$ for 5 minutes. A very thin layer of sediment was found on the bottom of the tubes. The sediment was resuspended in $1 \mathrm{~mL}$ PBS after carefully aspirating out all the supernatant. Urine samples were obtained from the urothelial carcinoma positive patients, which have been confirmed in Toronto General Hospital. The sample preparation procedure was almost the same with healthy samples. Since the cell density in cancerous samples was higher, only $20-50$ $\mathrm{mL}$ urine was collected. All samples were tested within 3 hours after collection.

Three types of urothelial cells have been identified within voided urine [60,63]. Basal cells (Fig. 5.1(a)), which rest on the basal membrane of bladder lining, represents rather small and cuboidal cells that typically present a hyperchromatic nucleus. Intermediate cells constitute the majority of the urothelium, displaying a clear and amphophilic cytoplasm, and possess a round to oval nucleus (Fig. 5.1(c)). The most superficial cells of the bladder lining are referred to as "umbrella" cells (Fig. 5.1(b)), which are characterized by an eosinophilic and wide cytoplasm, large rounded nucleus, frequently exhibiting bi-nucleation and even multi-nucleation, and usually displaying prominent nucleoli [63]. The malignant urothelial cells usually possess a higher nucleus to cytomplasm ratio and present granulous nucleus and cytoplasm (Fig. 5.1(d)). Since the basal cells and umbrella cells are extremely rare in the healthy urine sample and morphologically distinguishable from the malignant cells, we only focus on intermediate cells, which account for over $90 \%$ of the urothelial carcinoma. During experiments, the operator identified the intermedi- 
ate urothelial cells morphologically and then sent the images to experienced clinicians and urologists in Toronto General Hospital for confirmation. Data of uncertain cells was excluded.

\subsection{Result and Discussion}

The Young's modulus of individual healthy intermediate cells and cancerous urothelial cells was investigated using the micropipette aspiration system. All cells were prepared before measurement with the procedure described above. Data collected from 6 different clinical samples (urothelial carcinoma negative $n=13$, urothelial carcinoma positive $n=17$ ) yield average Young's modulus values (mean \pm standard-error) for all the healthy intermediate cells of $460 \pm 50 \mathrm{~Pa}$ and cancerous urothelial cells of $200 \pm 40 \mathrm{~Pa}$. A two-sample independent t-test conducted on the cancerous and healthy cell populations showed that the population means were significantly different from each other at a $95 \%$ confidence level $\left(P=5.8 \times 10^{-4}\right)$ (see Fig. 5.2(a)).

During experiments, we observed that if the nucleus occupies most of the space inside the cell membrane, when pipette aspiration was performed, the nucleus was partially aspirated into the pipette opening which affected the Young's modulus calculation, causing these cancerous cells with higher $\mathrm{NC}$ ratio to be stiffer than the cancerous cells with lower $\mathrm{NC}$ ratio. As a result, within the cancerous group, the two samples with higher NC ratio (nucleus to cytoplasm ratio) $(0.496 \pm 0.10)$ showed clearly different response to the aspiration pressure and possess higher measured Young's modulus compared with the two samples with lower NC ratio $(0.213 \pm 0.062)$ as shown in Fig. 5.2(b). Due to the interference of the cancerous cells with high NC ratio, Young's modulus alone can not be used as a trustworthy marker for clinical screening. However, as shown in Fig. 5.3, the Young's modulus of the urothelial cells can provide useful information for samples with smaller NC ratio. Fig. 5.4 is a scatter plot of the NC ratio and Young's modulus 


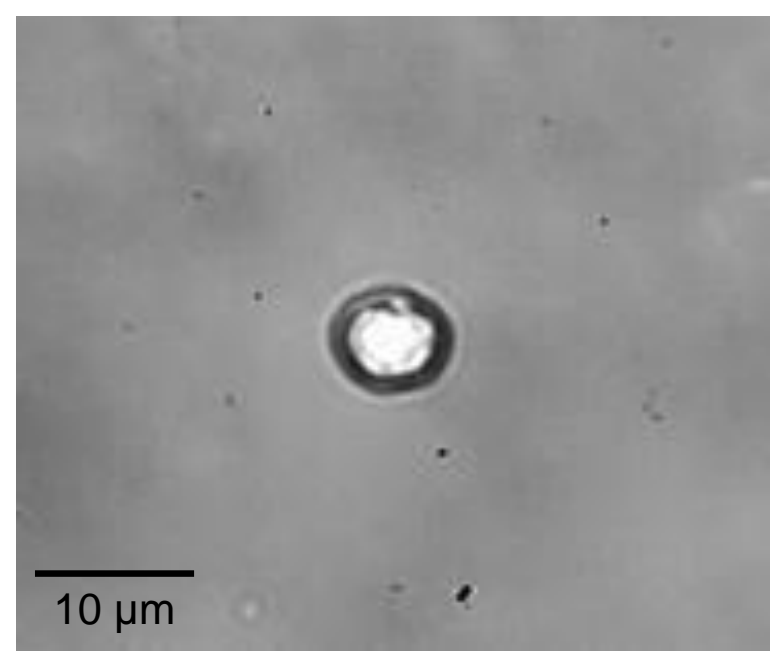

(a)

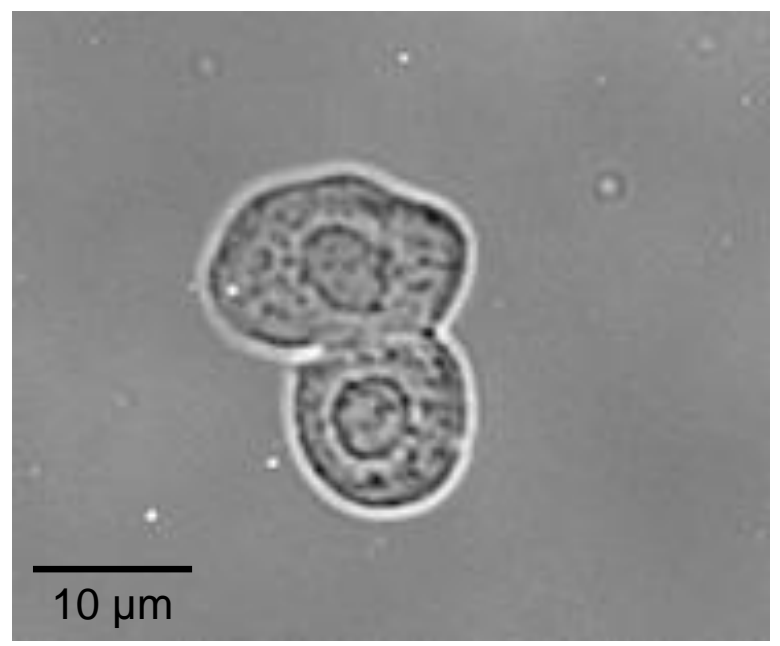

(c)

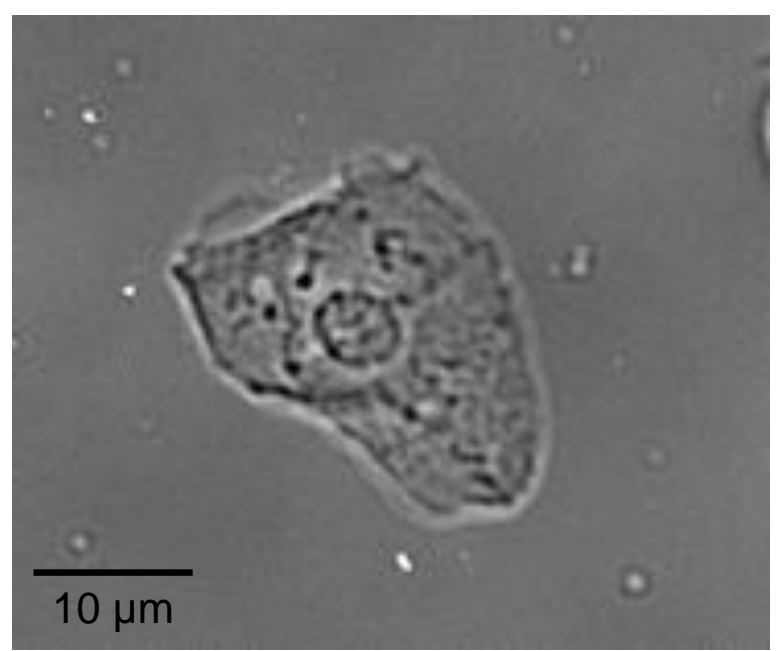

(b)

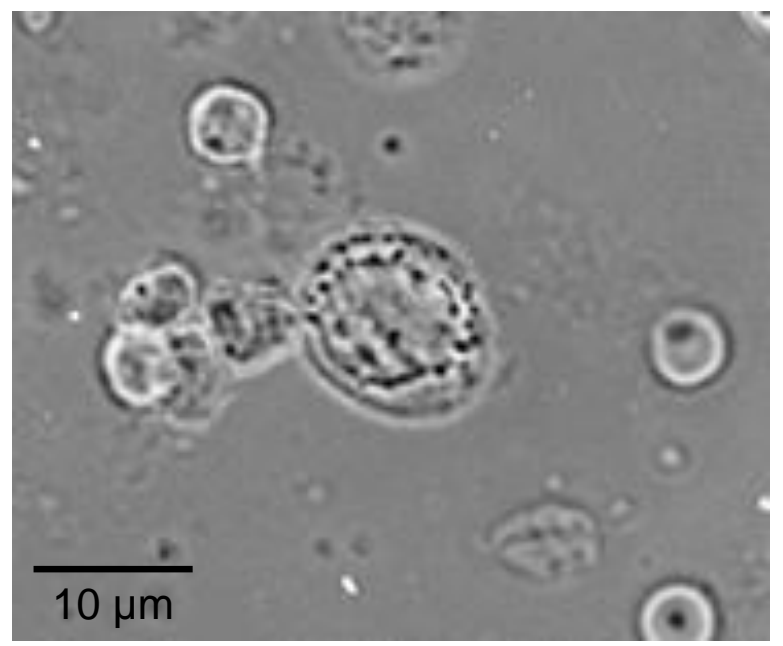

(d)

Figure 5.1: Representative morphologies of different urothelial cells present in human voided urine. (a) Basal cell, (b) umbrella cell, (c) intermediate cell and (d) cancerous urothelial cell. 
of the healthy and cancerous uthothelial cells. As shown is Fig. 5.4, for the normal samples and the cancerous samples with high $\mathrm{NC}$ ratio, the morphological difference of the $\mathrm{NC}$ ratio is so distinct that even a trained graduate students (authors) can easily distinguish. However, for the cancerous samples with comparable NC ratio, morphological distinguishing becomes more challenging. In this case, Young's modulus can serve as an effective marker for the identification of the cancerous cells.

According to the test results, cancerous cells are generally more deformable than normal cells, which can be understood by the physical necessity of the cancerous cells to be motile. This agrees with previous literature which found a decrease in the stiffness of human cancer cell lines and human samples with increasing metastatic efficiency using different single-cell in vitro biomechanical assays. Although there are a number of literatures on cancerous cells deferability changes compared with their healthy counter parts $[6,8,64]$, data of the urothelial cells in voided urine reported here have unique contributions. Firstly, artificial cell lines are good targets for developing new technologies, but the data generated from artificial cell lines lack directive significance in clinical applications and insights compared with real human samples. In addition, compared to other sources of human cancer cells, e.g., pleural fluid, urine samples can be easily accessed, prepared and tested.

The mechanical property of the urothelial cells in voided urine is more promising as a non-invasive supplementary tool for pathologists to improve diagnostic accuracy. Thirdly, since no biomarkers, complex preparation procedures and expensive infrastructures are involved, the Young's modulus measuring on urothelial cells will not increase the cost of a routine bladder cancer screening. However, due to the rare number of the cells present in the voided urine and the limitation on the throughput of pipette aspiration technology, the total number of the cells tested in this report is not high enough to establish a conclusive evaluation of the effectiveness of the usage of the mechanical maker for urothelial carcinoma diagnosis. The preliminary data reported in this thesis 
is aimed to evoke attention to this promising research topic and intrigue interests in the development of new techniques, e.g., microfluidic devices [64-66], which are capable of handling large volume and low density urine samples, and potentially usable in clinical applications.

\subsection{Conclusion}

In this study, cancerous urothelial cells and healthy intermediate urithelial cell were tested indicating important implications for the usage of mechanical properties as a supplementary biomarker for assisting morphological analysis. Our results suggest that a decrease of mechanical properties can be correlated to the metastatic states of urothelial cells in voided urine. Morphological overlap can often interfere the interpretation of the cytomorphological diagnosis of urothelial carcinoma, wherein the mechanical marker is able to provide additional information. Urothelial carcinoma is quite biochemically diverse, the data reported in this study is not sufficient enough to establish a criterion for using mechanical markers as a diagnostic tool in clinics, however, the preliminary results clearly show the potential of mechanical markers for low-cost and non-invasive detection and monitoring of urothilial carcinoma. 


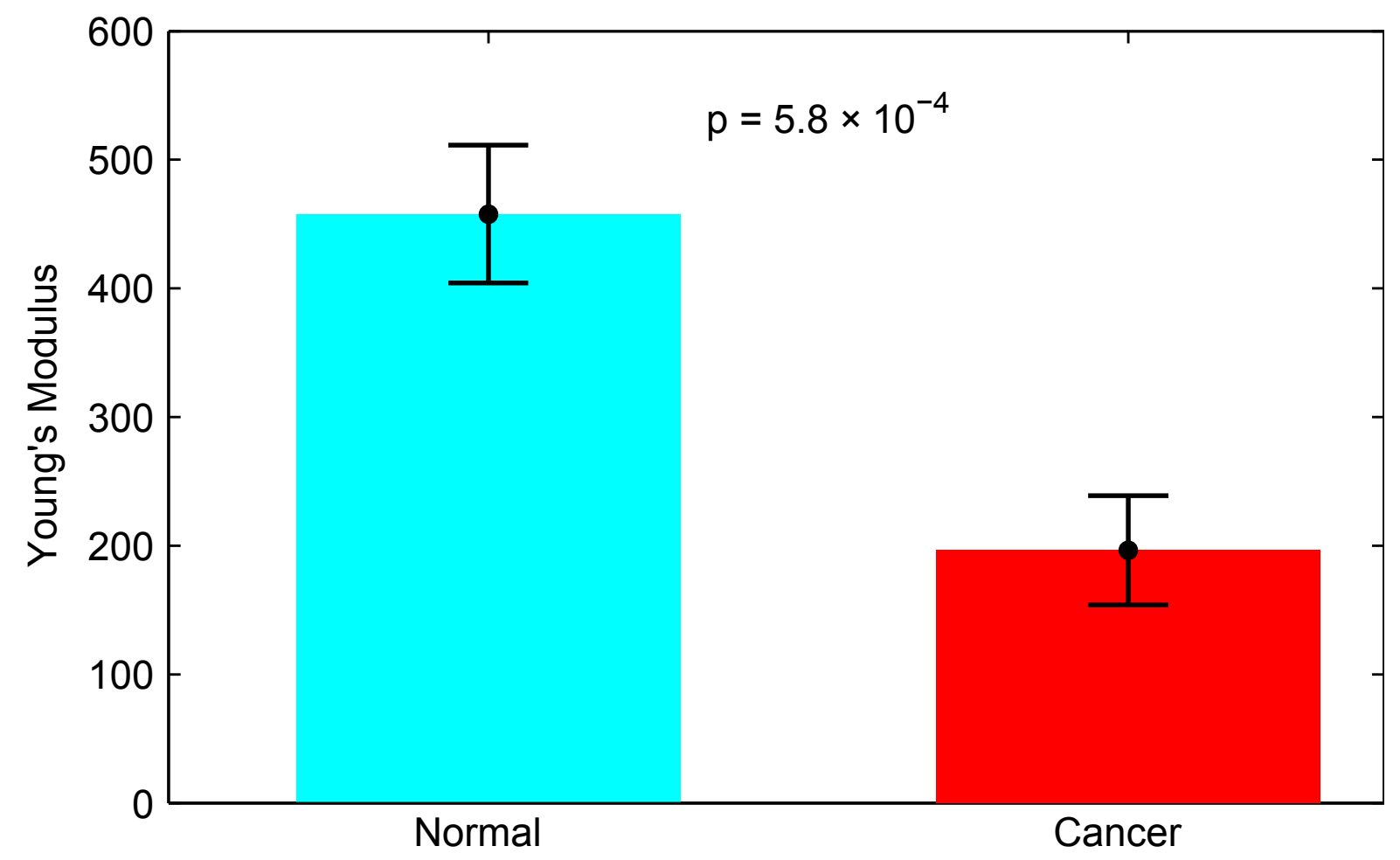

(a) Comparison between normal and tumor cells

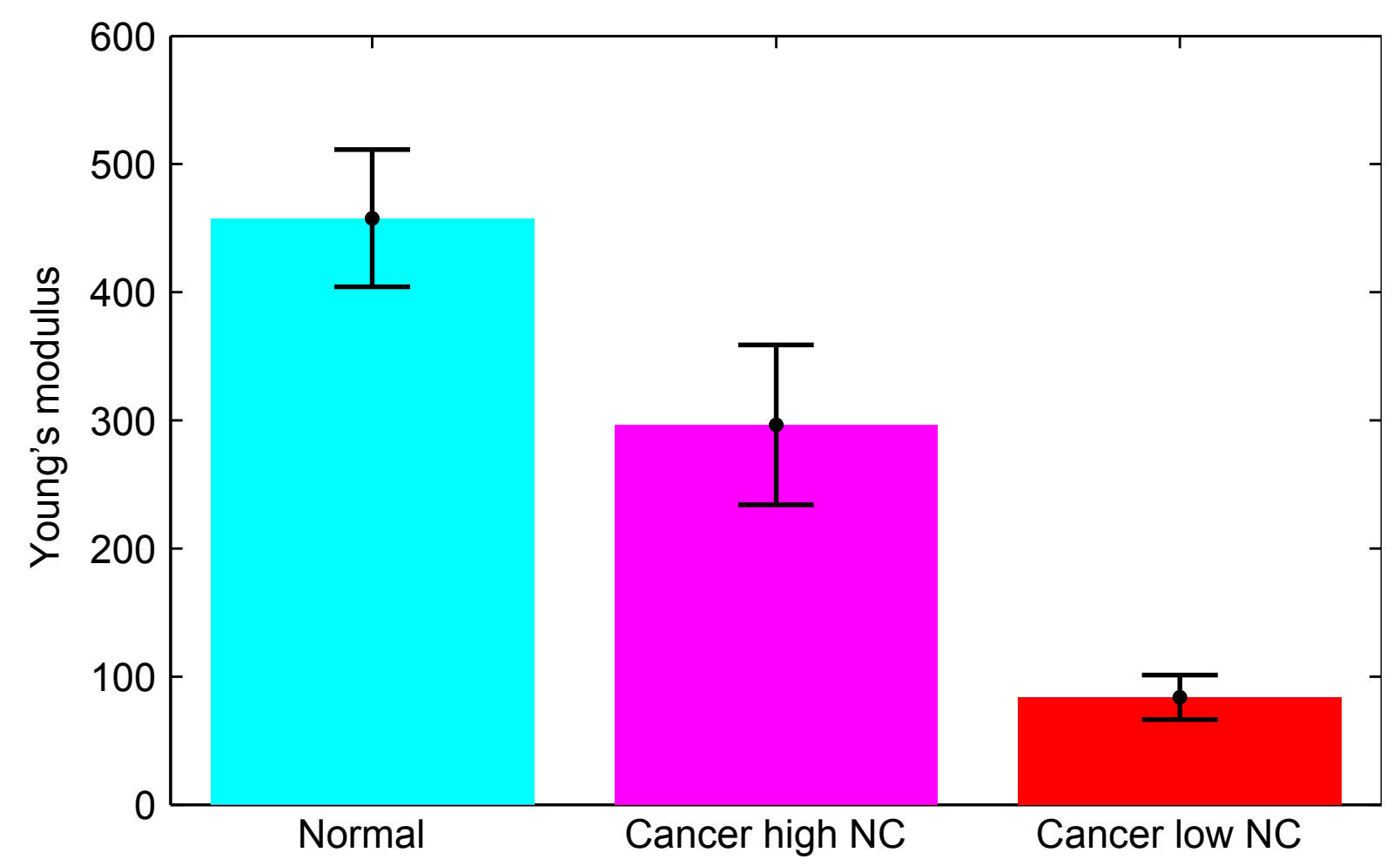

(b) Comparison among normal and tumor cells with high and low NC ratio

Figure 5.2: Young's Modulus results from micropipette aspiration testing of voided urine. (a) Young's modulus of normal intermediate cells (460 $\pm 50 P a, n=13$ ) and cancerous urothelial cells (200 $\pm 40 \mathrm{~Pa}, n=17$ ). (b) Young's modulus of normal intermediate cells

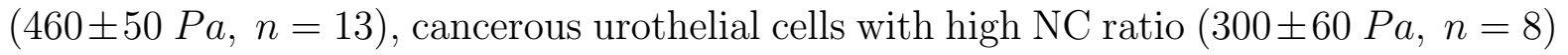
and cancerous urothelial cells with low NC ratio $(84 \pm 17 \mathrm{~Pa}, n=9)$. 


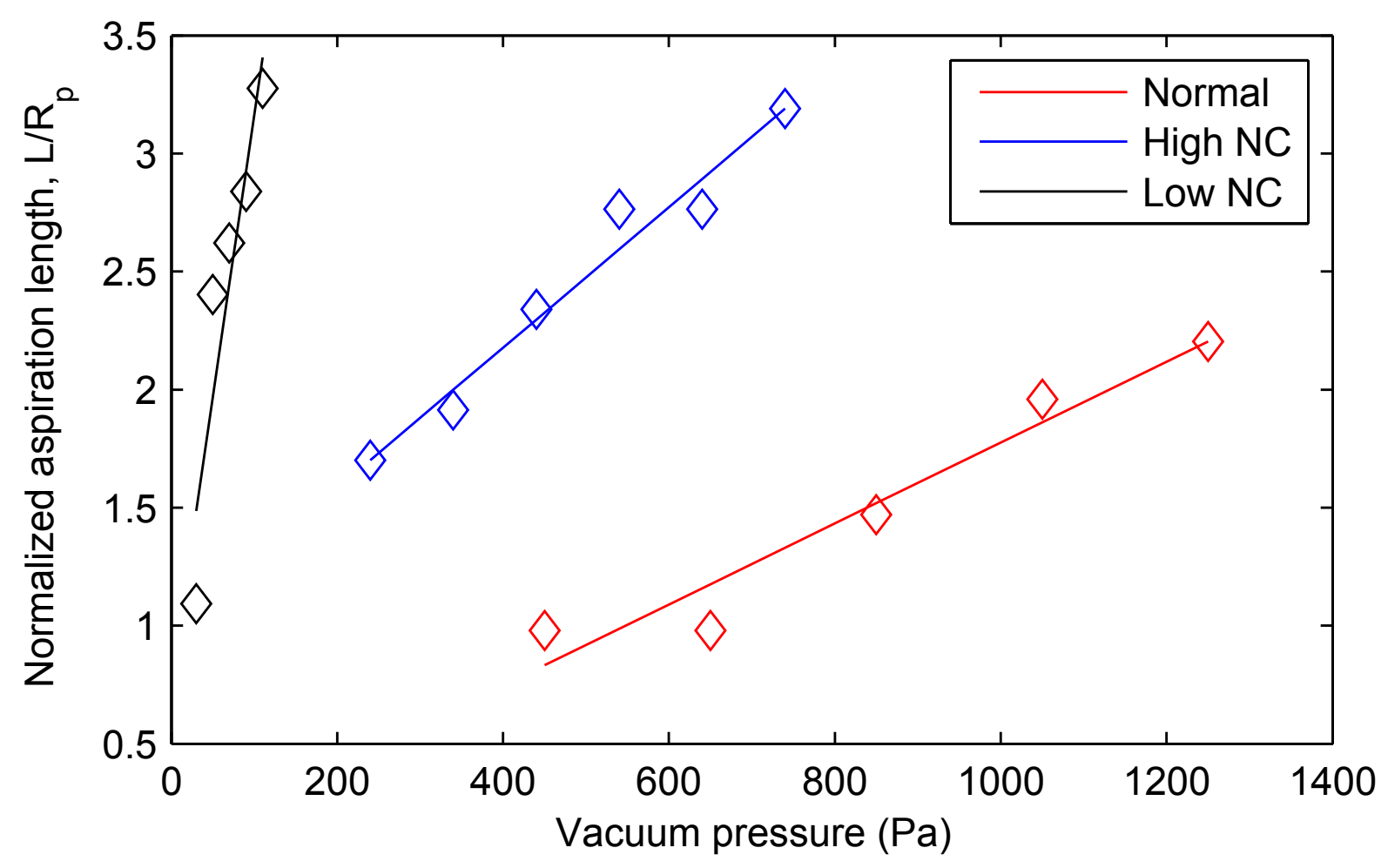

Figure 5.3: Comparison among three categories of cells. Experimental curve of normalized aspiration length vs. aspiration pressure of typical normal intermediate cells (red), cancerous urothelial cells with high $\mathrm{NC}$ ratio (blue) and cancerous urothelial cells with low $\mathrm{NC}$ ratio (black). 


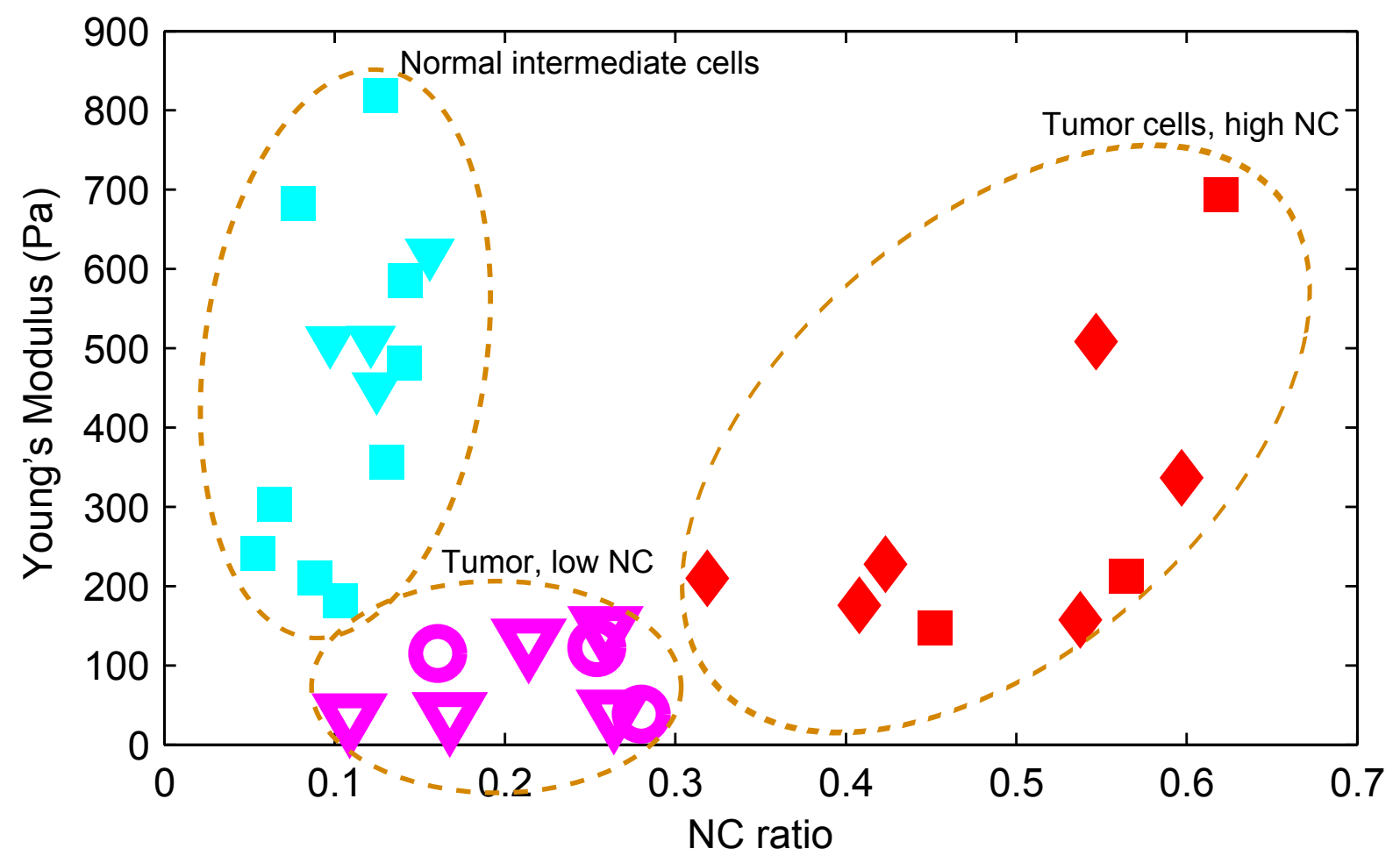

Figure 5.4: Scatter plot of NC ratio vs. Young's Modulus of normal intermediate cells and cancerous urothelial cells with both high $(<0.3)$ and low $(>0.3)$ NC ratio $(n=17)$. Data points of different shapes with the same color group present different donors. When the tumor cells have comparable NC ratio with normal intermediate cells, the Young's Modulus of cells can be used as an additional bio-marker, along with the NC ratio (morphological marker), the cells type can be better interpreted. 


\section{Chapter 6}

\section{Summary}

\subsection{Discussion}

For comparison purposes, manual micropipette aspiration was also performed by a proficient operator. In manual operation, the user looked into the eyepieces of the microscope and controlled the micropipette positions using a joystick. Comparing the speed of locating and homing the micropipette, the system was at least two times faster than the proficient operator (19 vs. 60 seconds). The system was also at least twice as fast in forming a seal between a cell and the micropipette ( 23 vs. 52 seconds). The time taken in the cell aspiration step was comparable since sufficient waiting time was required for cells to respond; however, we believe that the pressure profile was generated more accurately by the closed-loop controlled pressure pump in the automated system. It was observed that the cells experience a consistent seal forming experience due to use of accurately controlled pressure profile.

It would take much longer for less trained users in these steps in manual operation, while the automated system's performance and operation speed are user independent. In image processing, the system determined cell deformation parameters during cell aspiration in real time without the need for tedious, lengthy post processing. In comparison, 
it took the proficient user averagely 2 minutes per cell to manually make measurements in recorded images for elastic measurements and approximately 2 hours for viscoelastic characterization due to the high number of images captured.

\subsection{Conclusion}

In this research the micropipette aspiration of living cells widely used by researchers working on living cells fundamentals was automated. The automated system is capable of performing three types of experiments: (1) measurement of elastic properties of solidlike cells; (2) characterization of viscoelastic properties of solid-like cells; (3) viscosity measurement of liquid-like cells. This is achieved through integration of computer vision microscopy and robotic control algorithms.

The development of an automated system capable of performing automated cell manipulation is one of the key novelties of this thesis. For instance in the digital pressure pump, features such as full fluid re-routing, de-bubbling the fluid lines, limit-switches are

implemented to ensure a full-automation user experience. Another implemented novelty is the developed software. Despite the scope of the LabVIEW code, a systematic approach was taken to ensure all errors are handled properly. This feature was specially significant during the debugging and fine tuning the software parameters.

In the voided urine study, we learned that a single marker (mechanical) is not sufficient to distinguish the cell type. In other words, other markers such as morphology, electrical, and chemical characteristics should be used to increase the chance of labeling a cell correctly. This calls for a more advanced sytem capable of performing multiple testing on single cells 


\subsection{Contributions}

1. Development of a computer controllable pressure system capable of providing $\pm 2,500$ differential Pa pressure.

2. Establishment of an automated method or creating a seal between a suspended cell and micropipette opening.

3. Development of an image processing algorithm for measuring aspiration length.

4. Designed a task management system for handling the automation process efficiently.

\subsection{Future Works}

The following are examples of future works that can be undertaken:

1. Developing the second prototype of the digital pressure system with higher response time where dynamic pressure application is of critical.

2. Developing a more sophisticated vision algorithm using optical-flow and maximum likelihood methods to deal with background noise and debris in a more robust fashion.

3. Testing a larger voided urine population for studying the correlation between mechanical properties of the cells and the cancer state. 


\section{Bibliography}

[1] Z. Lu, C. Moraes, G. Ye, C. a. Simmons, and Y. Sun, "Single cell deposition and patterning with a robotic system." PloS one, vol. 5, no. 10, p. e13542, Jan. 2010.

[2] D.-H. Kim, P. K. Wong, J. Park, A. Levchenko, and Y. Sun, "Microengineered platforms for cell mechanobiology." Annual review of biomedical engineering, vol. 11, pp. 203-33, Jan. 2009.

[3] G. Bao and S. Suresh, "Cell and molecular mechanics of biological materials." Nature materials, vol. 2, no. 11, pp. 715-25, Nov. 2003.

[4] C. Zhu, G. Bao, and N. Wang, "Cell mechanics: mechanical response, cell adhesion, and molecular deformation." Annual review of biomedical engineering, vol. 2, pp. 189-226, Jan. 2000.

[5] B. Alberts, A. Johnson, J. Lewis, M. Raff, K. Roberts, and P. Walter, Molecular Biology of the Cell, Fourth Edition. Garland Science, 2002.

[6] S. Suresh, "Biomechanics and biophysics of cancer cells." Acta biomaterialia, vol. 3, no. 4, pp. 413-38, Jul. 2007.

[7] G. Y. H. Lee and C. T. Lim, "Biomechanics approaches to studying human diseases." Trends in biotechnology, vol. 25, no. 3, pp. 111-8, Mar. 2007. 
[8] S. E. Cross, Y.-S. Jin, J. Rao, and J. K. Gimzewski, "Nanomechanical analysis of cells from cancer patients." Nature nanotechnology, vol. 2, no. 12, pp. 780-3, Dec. 2007.

[9] W. R. Trickey, G. M. Lee, and F. Guilak, "Viscoelastic properties of chondrocytes from normal and osteoarthritic human cartilage." Journal of orthopaedic research : official publication of the Orthopaedic Research Society, vol. 18, no. 6, pp. 891-8, Nov. 2000.

[10] S. S. An, B. Fabry, X. Trepat, N. Wang, and J. J. Fredberg, "Do biophysical properties of the airway smooth muscle in culture predict airway hyperresponsiveness?" American journal of respiratory cell and molecular biology, vol. 35, no. 1, pp. 55-64, Jul. 2006.

[11] C. Lim, E. Zhou, a. Li, S. Vedula, and H. Fu, "Experimental techniques for single cell and single molecule biomechanics," Materials Science and Engineering: C, vol. 26, no. 8, pp. 1278-1288, Sep. 2006.

[12] L. H. Miller, S. Usami, and S. Chien, "Alteration in the rheologic properties of Plasmodium knowlesi-infected red cells. A possible mechanism for capillary obstruction." The Journal of clinical investigation, vol. 50, no. 7, pp. 1451-5, Jul. 1971.

[13] H. A. Cranston, C. W. Boylan, G. L. Carroll, S. P. Sutera, J. R. Williamson, I. Y. Gluzman, and D. J. Krogstad, "Plasmodium falciparum maturation abolishes physiologic red cell deformability." Science (New York, N.Y.), vol. 223, no. 4634, pp. 400-3, Jan. 1984.

[14] R. Suwanarusk, B. M. Cooke, A. M. Dondorp, K. Silamut, J. Sattabongkot, N. J. White, and R. Udomsangpetch, "The deformability of red blood cells parasitized 
by Plasmodium falciparum and P. vivax." The Journal of infectious diseases, vol. 189, no. 2, pp. 190-4, Jan. 2004.

[15] G. B. Nash, E. O’Brien, E. C. Gordon-Smith, and J. A. Dormandy, "Abnormalities in the mechanical properties of red blood cells caused by Plasmodium falciparum." Blood, vol. 74, no. 2, pp. 855-61, Aug. 1989.

[16] M. Paulitschke and G. B. Nash, "Membrane rigidity of red blood cells parasitized by different strains of Plasmodium falciparum." The Journal of laboratory and clinical medicine, vol. 122, no. 5, pp. 581-9, Nov. 1993.

[17] F. K. Glenister, "Contribution of parasite proteins to altered mechanical properties of malaria-infected red blood cells," Blood, vol. 99, no. 3, pp. 1060-1063, Feb. 2002.

[18] J. P. Mills, L. Qie, M. Dao, C. T. Lim, and S. Suresh, "Nonlinear elastic and viscoelastic deformation of the human red blood cell with optical tweezers." Mechanics $\&$ chemistry of biosystems : $M C B$, vol. 1, no. 3, pp. 169-80, Sep. 2004.

[19] S. Suresh, J. Spatz, J. P. Mills, A. Micoulet, M. Dao, C. T. Lim, M. Beil, and T. Seufferlein, "Connections between single-cell biomechanics and human disease states: gastrointestinal cancer and malaria." Acta biomaterialia, vol. 1, no. 1, pp. 15-30, Jan. 2005.

[20] J. P. Shelby, J. White, K. Ganesan, P. K. Rathod, and D. T. Chiu, "A microfluidic model for single-cell capillary obstruction by Plasmodium falciparum-infected erythrocytes." Proceedings of the National Academy of Sciences of the United States of America, vol. 100, no. 25, pp. 14618-22, Dec. 2003.

[21] M. M. Brandão, A. Fontes, M. L. Barjas-Castro, L. C. Barbosa, F. F. Costa, C. L. Cesar, and S. T. O. Saad, "Optical tweezers for measuring red blood cell elasticity: application to the study of drug response in sickle cell disease." European journal of haematology, vol. 70, no. 4, pp. 207-11, Apr. 2003. 
[22] E. A. Evans and P. L. La Celle, "Intrinsic material properties of the erythrocyte membrane indicated by mechanical analysis of deformation." Blood, vol. 45, no. 1, pp. 29-43, Jan. 1975.

[23] R. M. Hochmuth, P. R. Worthy, and E. A. Evans, "Red cell extensional recovery and the determination of membrane viscosity." Biophysical journal, vol. 26, no. 1, pp. 101-14, Apr. 1979.

[24] G. B. Nash, C. S. Johnson, and H. J. Meiselman, "Mechanical properties of oxygenated red blood cells in sickle cell (HbSS) disease." Blood, vol. 63, no. 1, pp. 73-82, Jan. 1984.

[25] B. Fabry, G. Maksym, J. Butler, M. Glogauer, D. Navajas, and J. Fredberg, "Scaling the Microrheology of Living Cells," Physical Review Letters, vol. 87, no. 14, pp. 1-4, Sep. 2001.

[26] J. P. Mills, L. Qie, M. Dao, C. T. Lim, and S. Suresh, "Nonlinear elastic and viscoelastic deformation of the human red blood cell with optical tweezers." Mechanics $\mathscr{E}$ chemistry of biosystems : MCB, vol. 1, no. 3, pp. 169-80, Sep. 2004.

[27] B. J. Haupt, a. E. Pelling, and M. a. Horton, "Integrated confocal and scanning probe microscopy for biomedical research." TheScientificWorldJournal, vol. 6, pp. 1609-18, Jan. 2006.

[28] B. Y. J. M. Mitchison and M. M. Swann, "THE MECHANICAL PROPERTIES OF THE CELL," Journal of Experimental Biology, vol. 31, pp. 461-472, 1954.

[29] R. M. Hochmuth, "Micropipette aspiration of living cells." Journal of biomechanics, vol. 33, no. 1, pp. 15-22, Jan. 2000. 
[30] E. Evans and a. Yeung, "Apparent viscosity and cortical tension of blood granulocytes determined by micropipet aspiration." Biophysical journal, vol. 56, no. 1, pp. 151-60, Jul. 1989.

[31] D. P. Theret, M. J. Levesque, M. Sato, R. M. Nerem, and L. T. Wheeler, "The application of a homogeneous half-space model in the analysis of endothelial cell micropipette measurements." Journal of biomechanical engineering, vol. 110, no. 3, pp. 190-9, Aug. 1988.

[32] M. Sato, D. P. Theret, L. T. Wheeler, N. Ohshima, and R. M. Nerem, "Application of the Micropipette Technique to the Measurement of Cultured Porcine Aortic Endothelial Cell Viscoelastic Properties," Journal of Biomechanical Engineering, vol. 112 , no. 3, p. 263, 1990.

[33] D. Needham and R. M. Hochmuth, "Rapid flow of passive neutrophils into a 4 microns pipet and measurement of cytoplasmic viscosity." Journal of biomechanical engineering, vol. 112, no. 3, pp. 269-76, Aug. 1990.

[34] J. Y. Shao and R. M. Hochmuth, "The resistance to flow of individual human neutrophils in glass capillary tubes with diameters between 4.65 and 7.75 microns." Microcirculation (New York, N.Y. : 1994), vol. 4, no. 1, pp. 61-74, Mar. 1997.

[35] A. J. Engler, S. Sen, H. L. Sweeney, and D. E. Discher, "Matrix elasticity directs stem cell lineage specification." Cell, vol. 126, no. 4, pp. 677-89, Aug. 2006.

[36] F. J. Byfield, H. Aranda-Espinoza, V. G. Romanenko, G. H. Rothblat, and I. Levitan, "Cholesterol depletion increases membrane stiffness of aortic endothelial cells." Biophysical journal, vol. 87, no. 5, pp. 3336-43, Nov. 2004.

[37] C. T. Lim, E. H. Zhou, and S. T. Quek, "Mechanical models for living cells-a review." Journal of biomechanics, vol. 39, no. 2, pp. 195-216, Jan. 2006. 
[38] W. R. Jones, H. P. Ting-Beall, G. M. Lee, S. S. Kelley, R. M. Hochmuth, and F. Guilak, "Alterations in the Young's modulus and volumetric properties of chondrocytes isolated from normal and osteoarthritic human cartilage." Journal of biomechanics, vol. 32, no. 2, pp. 119-27, Feb. 1999.

[39] M. Sato, M. J. Levesque, and R. M. Nerem, "Micropipette aspiration of cultured bovine aortic endothelial cells exposed to shear stress." Arteriosclerosis (Dallas, Tex.), vol. 7, no. 3, pp. 276-86, 1987.

[40] E. Evans and A. Yeung, "Apparent viscosity and cortical tension of blood granulocytes determined by micropipet aspiration." Biophysical journal, vol. 56, no. 1, pp. 151-60, Jul. 1989.

[41] R. M. Hochmuth, "Measuring the mechanical properties of individual human blood cells." Journal of biomechanical engineering, vol. 115, no. 4B, pp. 515-9, Nov. 1993.

[42] V. Heinrich and W. Rawicz, "Automated, high-resolution micropipet aspiration reveals new insight into the physical properties of fluid membranes." Langmuir : the ACS journal of surfaces and colloids, vol. 21, no. 5, pp. 1962-71, Mar. 2005.

[43] X. Liu, Y. Wang, and Y. Sun, "Cell Contour Tracking and Data Synchronization for Real-Time, High-Accuracy Micropipette Aspiration," IEEE Transactions on Automation Science and Engineering, vol. 6, no. 3, pp. 536-543, Jul. 2009.

[44] R. Schreier and G. C. Temes, Understanding Delta-Sigma Data Converters. Wiley-IEEE Press, 2005, vol. 22, no. July.

[45] K. Hashimoto, "A review on vision-based control of robot manipulators," Advanced Robotics, vol. 17, no. 10, pp. 969-991, Dec. 2003.

[46] W. J. Rugh and J. S. Shamma, "Research on gain scheduling," Automatica, vol. 36, no. 10, pp. 1401-1425, Oct. 2000. 
[47] D. J. Leith and W. E. Leithead, "Survey of gain-scheduling analysis and design," International Journal of Control, vol. 73, no. 11, pp. 1001-1025, Jan. 2000.

[48] J. P. Lewis, "Fast normalized cross-correlation," in Vision Interface, vol. 10, no. 1, Citeseer. Canadian Image Processing and Pattern Recognition Society, 1995, pp. 120-123.

[49] E. R. Dougherty and R. A. Lotufo, Hands-on Morphological Image Processing. 1000 20th Street, Bellingham, WA 98227-0010 USA: SPIE, Jul. 2003.

[50] C. a. Simmons, "Aortic valve mechanics: an emerging role for the endothelium." Journal of the American College of Cardiology, vol. 53, no. 16, pp. 1456-8, Apr. 2009.

[51] W. D. Merryman, I. Youn, H. D. Lukoff, P. M. Krueger, F. Guilak, R. a. Hopkins, and M. S. Sacks, "Correlation between heart valve interstitial cell stiffness and transvalvular pressure: implications for collagen biosynthesis." American journal of physiology. Heart and circulatory physiology, vol. 290, no. 1, pp. H224-31, Jan. 2006.

[52] M. a. Tsai, R. E. Waugh, and P. C. Keng, "Cell cycle-dependence of HL-60 cell deformability." Biophysical journal, vol. 70, no. 4, pp. 2023-9, Apr. 1996.

[53] M. a. Tsai, R. S. Frank, and R. E. Waugh, "Passive mechanical behavior of human neutrophils: power-law fluid." Biophysical journal, vol. 65, no. 5, pp. 2078-88, Nov. 1993.

[54] P. C. Black, G. a. Brown, and C. P. Dinney, "Molecular markers of urothelial cancer and their use in the monitoring of superficial urothelial cancer." Journal of clinical oncology : official journal of the American Society of Clinical Oncology, vol. 24 , no. 35 , pp. 5528-35, Dec. 2006. 
[55] N. D. Freedman, D. T. Silverman, A. R. Hollenbeck, A. Schatzkin, and C. C. Abnet, "Association between smoking and risk of bladder cancer among men and women." JAMA : the journal of the American Medical Association, vol. 306, no. 7, pp. $737-45$, Aug. 2011.

[56] B. R. Konety, G. F. Joyce, and M. Wise, "Bladder and upper tract urothelial cancer." The Journal of urology, vol. 177, no. 5, pp. 1636-45, May 2007.

[57] S. F. Shariat, J. a. Karam, Y. Lotan, and P. I. Karakiewizc, "Critical evaluation of urinary markers for bladder cancer detection and monitoring." Reviews in urology, vol. 10, no. 2, pp. 120-35, Jan. 2008.

[58] B. Planz, E. Jochims, T. Deix, H. P. Caspers, G. Jakse, and A. Boecking, "The role of urinary cytology for detection of bladder cancer." European journal of surgical oncology : the journal of the European Society of Surgical Oncology and the British Association of Surgical Oncology, vol. 31, no. 3, pp. 304-8, May 2005.

[59] C. Pfister, D. Chautard, M. Devonec, P. Perrin, D. Chopin, P. Rischmann, O. Bouchot, D. Beurton, C. Coulange, and J.-J. Rambeaud, "Immunocyt test improves the diagnostic accuracy of urinary cytology: results of a French multicenter study." The Journal of urology, vol. 169, no. 3, pp. 921-4, Mar. 2003.

[60] N. P. Caraway and R. L. Katz, "A review on the current state of urine cytology emphasizing the role of fluorescence in situ hybridization as an adjunct to diagnosis." Cancer cytopathology, vol. 118, no. 4, pp. 175-83, Aug. 2010.

[61] J. Messer, S. F. Shariat, J. C. Brien, M. P. Herman, C. K. Ng, D. S. Scherr, B. Scoll, R. G. Uzzo, M. Wille, S. E. Eggener, G. Steinberg, J. D. Terrell, S. M. Lucas, Y. Lotan, S. A. Boorjian, and J. D. Raman, "Urinary cytology has a poor performance for predicting invasive or high-grade upper-tract urothelial carcinoma." BJU international, vol. 108, no. 5, pp. 701-5, Oct. 2011. 
[62] M. Makale, "Cellular mechanobiology and cancer metastasis." Birth defects research. Part C, Embryo today : reviews, vol. 81, no. 4, pp. 329-43, Dec. 2007.

[63] M. Castillo-Martin, J. Domingo-Domenech, O. Karni-Schmidt, T. Matos, and C. Cordon-Cardo, "Molecular pathways of urothelial development and bladder tumorigenesis." Urologic oncology, vol. 28, no. 4, pp. 401-8, 2010.

[64] T. W. Remmerbach, F. Wottawah, J. Dietrich, B. Lincoln, C. Wittekind, and J. Guck, "Oral cancer diagnosis by mechanical phenotyping." Cancer research, vol. 69, no. 5, pp. 1728-32, Mar. 2009.

[65] D. R. Gossett, H. T. K. Tse, S. A. Lee, Y. Ying, A. G. Lindgren, O. O. Yang, J. Rao, A. T. Clark, and D. Di Carlo, "Hydrodynamic stretching of single cells for large population mechanical phenotyping." Proceedings of the National Academy of Sciences of the United States of America, vol. 109, no. 20, pp. 7630-5, May 2012.

[66] Y. Zheng, E. Shojaei-Baghini, A. Azad, C. Wang, and Y. Sun, "High-throughput biophysical measurement of human red blood cells." Lab on a chip, May 2012. 